\title{
Chemical Diversity and Biological Activity of Secondary Metabolites from Soft Coral Genus Sinularia since 2013
}

\author{
Xia Yan ${ }^{1}$, Jing Liu ${ }^{1}$, Xue Leng ${ }^{1}$ and Han Ouyang ${ }^{2, *}$ \\ 1 Li Dak Sum Yip Yio Chin Kenneth Li Marine Biopharmaceutical Research Center, Department of Marine \\ Pharmacy, College of Food and Pharmaceutical Sciences, Ningbo University, Ningbo 315800, China; \\ yanxia@nbu.edu.cn (X.Y.); liujingsally@163.com (J.L.); 1xue1520@163.com (X.L.) \\ 2 Institute of Drug Discovery Technology, Ningbo University, Ningbo 315211, China \\ * Correspondence: ouyanghan@nbu.edu.cn; Tel.: +86-574-87609771
}

check for updates

Citation: Yan, X.; Liu, J.; Leng, X.; Ouyang, H. Chemical Diversity and Biological Activity of Secondary Metabolites from Soft Coral Genus Sinularia since 2013. Mar. Drugs 2021, 19, 335. https://doi.org/10.3390/ md19060335

Academic Editor: Marialuisa Menna

Received: 20 May 2021

Accepted: 10 June 2021

Published: 11 June 2021

Publisher's Note: MDPI stays neutral with regard to jurisdictional claims in published maps and institutional affiliations.

Copyright: (c) 2021 by the authors. Licensee MDPI, Basel, Switzerland. This article is an open access article distributed under the terms and conditions of the Creative Commons Attribution (CC BY) license (https:// creativecommons.org/licenses/by/ $4.0 /)$.

\begin{abstract}
Sinularia is one of the conspicuous soft coral species widely distributed in the world's oceans at a depth of about $12 \mathrm{~m}$. Secondary metabolites from the genus Sinularia show great chemical diversity. More than 700 secondary metabolites have been reported to date, including terpenoids, norterpenoids, steroids/steroidal glycosides, and other types. They showed a broad range of potent biological activities. There were detailed reviews on the terpenoids from Sinularia in 2013, and now, it still plays a vital role in the innovation of lead compounds for drug development. The structures, names, and pharmacological activities of compounds isolated from the genus Sinularia from 2013 to March 2021 are summarized in this review.
\end{abstract}

Keywords: soft coral; Sinularia; secondary metabolites; bioactivity

\section{Introduction}

Secondary metabolites from marine organisms represented a plentiful source of structurally diverse and natural bioactive products. The soft corals of genus Sinularia (phylum Cnidaria, class Anthozoa, subclass Octocorallia, order Alcyonacea, family Alcyoniidae) inhabiting the coral reefs or rocks in shallow water constitutes a dominant portion of the biomass in the tropical coral reef systems in the world. There are more than 90 species of Sinularia, and more than 50 species have been chemically evaluated from 1975 to 2013 [1]. As reported, Sinularia is well-known to produce a wealth of diverse and complex secondary metabolites, such as sesquiterpenes (10\%), diterpenes (46\%), norsesquiterpenes $(2 \%)$, norditerpenes $(9 \%)$, steroids / steroidal glycosides $(22 \%)$, and other types $(11 \%)$ (Figure 1) [1-3]. These metabolites exhibit a wide range of biological activities, such as cytotoxic, anti-inflammatory, antifouling, and anti-microbials [4-14].

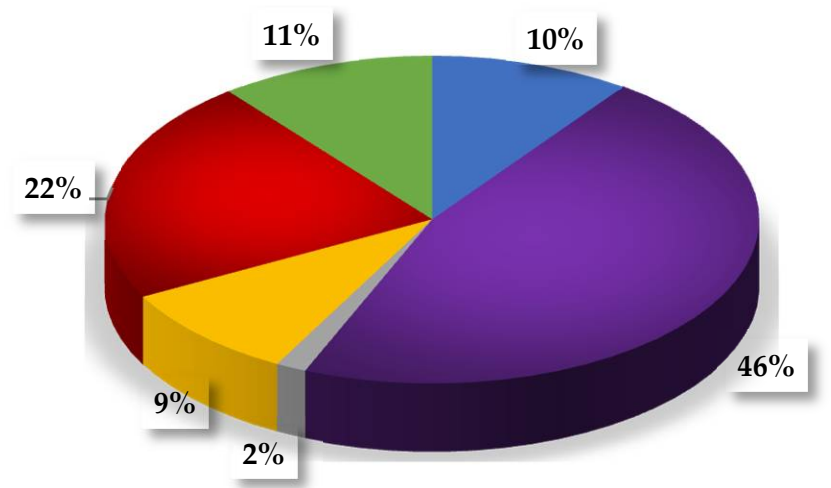

- Sesquiterpene

घiterpene

Norsesquiterpene

Norditerpene

- Steroid/steroidal glycoside - Others

Figure 1. Compounds from genus Sinularia with different ratios of structural types. 
There are some published literature reviews on the genus Sinularia. For example, Liang et al. [15] reviewed the secondary metabolites obtained from Sinularia and summarized the different types of chemical structures and/or biological investigations within a literature survey from 1975 to April 2013. Chen et al. [1] reviewed the terpenes from the soft coral of the genus Sinularia, highlighting their novel chemistry and pharmacological activities. Sheu et al. [16] reviewed the structures, names, and bioactivities of 75 marine diterpenoids from octocorals possessing a hydroperoxy group, of which 41 compounds exhibited potential biomedical activities. Lakshmi et al. [17] summarized the chemical constituents of $\approx 40 \mathrm{~S}$. sp. covering a period of 1975-2004. Rodrigues et al. [18] reviewed the new isolated cembranoid derivatives from species of genera Sarcophyton, Sinularia, and Lobophytum as well as their biological properties during 2016-2018. Especially, the current review focuses on the chemical structures and the biological activities of secondary metabolites obtained from soft coral genus S. since 2013; the Scifinder and Web of Science databases were used for research (Table 1$)$.

Table 1. Chemically studied Sinularia soft coral from 2013 to March 2021.

\begin{tabular}{|c|c|c|c|}
\hline Species & Sampling Locations & Authors & Ref. \\
\hline S. humilis & Ximao Island, Hainan Province, China & Li-Li Sun; Xu-Wen Li * & [4] \\
\hline S. variabilis & the Persian Gulf & Pardis Mohammadi Pour; Mustafa Ghanadian * & [19] \\
\hline S. scabra & Pingtung, southern Taiwan & Yu-Hung Lu; Mohamed El-Shazly * & [20] \\
\hline S. polydactyla & Xisha Islands, Hainan Province, China & Fei Ye; Xu-wen Li * & [21] \\
\hline S. sp. & Yalong bay, Sanya, China & Min Yang; Yue-Wei Guo * & [22] \\
\hline S. depressa & Ximao Island, Hainan Province, China & Min Yang; Yue-Wei Guo * & [5] \\
\hline S. polydactyla & Hurghada, Egypt & Mohamed A. Tammam; Vassilios Roussis * & [6] \\
\hline S. erecta & Ximao Island, Hainan Province, China & Jiao Liu; Yue-Wei Guo * & [2] \\
\hline S. erecta & Ximao Island, Hainan Province, China & Jiao Liu; Yue-Wei Guo * & [7] \\
\hline S. humilis & Ximao Island, Hainan Province, China & Jie Li; Xu-wen Li * & [23] \\
\hline S. scabra & Xigu Island, Hainan Province, China & Wan-Xiang Cui; Yue-Wei Guo * & [24] \\
\hline S. polydactyla & Ximao Island, Hainan Province, China & Wan-Xiang Cui; Yue-Wei Guo * & [24] \\
\hline S. leptoclados & Pingtung, Taiwan & Yu-Chia Chang; Tsong-Long Hwang * & [25] \\
\hline S. tumulosa & Ximao Island, Hainan Province, China & You-Sheng Cai; Yue-Wei Guo * & [8] \\
\hline S. scabra & Grand Island, NY, USA & Min Yang; Xu-wen Li * & [26] \\
\hline S. flexibilis & Xidao Island, Hainan & Qihao Wu; Yue-Wei Guo * & [27] \\
\hline S. multiflora & Xisha Islands of the South China Sea & Zheng Wang; Guo-Qiang Li * & [28] \\
\hline S. flexibilis & Mantanani Island, Sabah, Malaysia & Chin-Soon Phan; Takashi Kamada * & [29] \\
\hline S. hirta & Yalong Bay, Hainan, China & Si-Qi Lu; Guan-Ying Han * & [30] \\
\hline S. sp. & Zhanjiang, Guangdong Province, China & Wei Lai; Shi-Hai Xu * & [31] \\
\hline S. sp. & Xisha Island, South China Sea, China & Cheng-Shi Jiang; Yue-Wei Guo * & [32] \\
\hline S. sp. & Xisha Island, South China Sea, China & Cheng-Shi Jiang; Yue-Wei Guo * & [9] \\
\hline S. digitata & Tho Chu island, Phu Quoc, Kien Giang, Vietnam & Nguyen Thi Huong; Nguyen Hoai Nam * & [33] \\
\hline S. polydactyla & Xisha Island, South China Sea, China & Fei Ye; Yue-Wei Guo * & [34] \\
\hline S. flexibilis & Liuqiu, Taiwan & Chia-Hua Wu; Jyh-Horng Sheu * & [35] \\
\hline S. sp. & Yongxing Island, Xisha Islands, the South China Sea & Guo-Fei Qin; Guo-Qiang Li * & [10] \\
\hline S. sp. & Ximao Island, Hainan Province, China & Song-Wei Li; Yue-Wei Guo * & [11] \\
\hline S. sp. & Mantanani Island, Sabah & Takashi Kamada; Charles S. Vairappan * & [36] \\
\hline S. flexibilis & Mengalum Island, Sabah & Takashi Kamada; Charles S. Vairappan * & [37] \\
\hline S. erecta & $\mathrm{Cu}$ Lao Cham island, Quang Nam, Vietnam & Nguyen Thi Huong; Chau Van Minh * & [38] \\
\hline S. nanolobata & San-Shin-Tai, Taitong County, Taiwan & Fu-Yun Hsu; Chang-Yih Duh * & [39] \\
\hline S. cf. molesta & the Paracel Islands, the South China Sea & Mei-Jun Chu; Guo-Qiang Li * & [40] \\
\hline S. polydactyla & Xisha Island, the South China Sea & Fei Ye; Yue-Wei Guo * & [41] \\
\hline S. flexibilis & Sanya Bay, Hainan Island, China & Jia Wang; Sheng An Tang * & [42] \\
\hline S. brassica & Con Co Island, Quangtri province, Vietnam & Hong Hanh Thi Tran; Chau Van Minh * & [43] \\
\hline S. nanolobata & Lang Co, Hue, Vietnam & Ninh Thi Ngoc; Chau Van Minh * & [44] \\
\hline S. conferta & Con Co island, Quangtri, Vietnam & Ninh Thi Ngoc; Chau Van Minh * & [45] \\
\hline S. leptoclados & Con Co island, Quangtri, Vietnam & Ninh Thi Ngoc; Chau Van Minh * & [46] \\
\hline S. terspilli & Hurghada, Egypt & Rabab Mohammed; Mahmoud A. ElSohly * & [47] \\
\hline S. brassica & Cultured, Taiwan & Chiung-Yao Huang; Jyh-Horng Sheu * & [12] \\
\hline S. brassica & Cultured, Taiwan & Chiung-Yao Huang; Jyh-Horng Sheu * & [48] \\
\hline
\end{tabular}


Table 1. Cont.

\begin{tabular}{|c|c|c|c|}
\hline Species & Sampling Locations & Authors & Ref. \\
\hline S. verruca & Ximao Island, Hainan Province, China & Weiping Yuan; Pengcheng Yan * & [49] \\
\hline S. sp. & Zhanjiang, Guangdong Province, China & Huan Sun; Shi-Hai Xu * & [50] \\
\hline S. sp. & Irabu Island, Okinawa, Japan & Prodip K. Roy; Katsuhiro Ueda * & [51] \\
\hline S. vanderlandi & Madagascan & Rahelivao M.; Hans-Joachim Knölker * & [52] \\
\hline S. sp. & Mantanani Island, Sabah, Malaysia & Chin-Soon Phan; Charles S. Vairappan * & [53] \\
\hline S. microspiculata & Da Den, Quangninh, Vietnam, & Nguyen Van Thanh; Chau Van Minh * & [54] \\
\hline S. nanolobata & Lang Co., Hue, Vietnam & Ninh Thi Ngoc; Chau Van Minh * & [55] \\
\hline S. lochmodes & Northeast corner of Taiwan & Yun-Sheng Lin; Jyh-Horng Sheu * & [56] \\
\hline S. erecta & Dongsha Atoll & Chiung-Yao Huang; Jyh-Horng Sheu * & [3] \\
\hline S. polydactyla & Red Sea, Hurghada, Egyptian & Mohamed-Elamir F. Hegazy; Paul W. Paré * & [57] \\
\hline S. inelegans & Mandapam, the Gulfof Mannar, India & Bhujanga Rao Chitturi * & [58] \\
\hline S. nanolobata & Jihui Fishing Port, Taitung County, Taiwan & Chih-Hua Chao; Jyh-Horng Sheu * & [59] \\
\hline S. acuta & Weizhou Island, Guangxi Province, China & Nai-Xia Zhang; Guo-Qiang Li * & [60] \\
\hline S. numerosa & Cultured, Taiwan & Chen-Ting Yin; Ping-Jyun Sung * & [61] \\
\hline S. sp. & Dongluo Island, Hainan Province, China & Bin Yang; Yonghong Liu * & [62] \\
\hline S. flexibilis & Cultured, Taiwan & Tsung-Chang Tsai; Jui-Hsin Su * & [63] \\
\hline S. gaweli & Sansiantai, Taitung County, Taiwan & Wun-Jie Lin; Ping-Jyun Sung * & [64] \\
\hline S. flexibilis & Yalong Bay, Hainan Province, China, & Wen-Ting Chen; Yue-Wei Guo * & [65] \\
\hline S. numerosa & Cultured, Taiwan & Wu-Fu Chen; Ping-Jyun Sung * & [66] \\
\hline S. nanolobata & Sianglu Islet, Penghu Islands, Taiwan & Chih-Hua Chao; Jyh-Horng Sheu * & [67] \\
\hline S. sp. & Dongluo Island, Hainan Province, China & Bin Yang; Yonghong Liu * & [68] \\
\hline S. arborea & Taiwan & Li-Hsueh Wang; Ping-Jyun Sung * & [69] \\
\hline S. kavarattiensis & Mandapam, Tamil Nadu, India & S Rajaram; Y Venkateswarlu * & [70] \\
\hline S. kavarattiensis & Rameshwaram, Tamil Nadu, India & Katja-Emilia Lillsunde; Päivi Tammela * & [71] \\
\hline S. sp. & Sanya Bay, Hainan Island, China & Ling-Fang Lei; Cui-Xian Zhang * & [72] \\
\hline S. depressa & Lingshui Bay, Hainan Province, China & Cheng-shi Jiang; Yue-Wei Guo * & [73] \\
\hline S. flexibilis & Yalong Bay, Hainan Province, China & Wen-Ting Chen; Yue-Wei Guo * & [74] \\
\hline S. arborea & Taiwan & Kuan-Hua Chen; Ping-Jyun Sung * & [75] \\
\hline S. capillosa & Sanya Bay, Hainan Island, China & Dawei Chen; Wenhan Lin * & [76] \\
\hline S. sp. & Ximao island, Hainan Province, China & Jian Yin; Pengcheng Yan * & [77] \\
\hline S. sp. & Dongluo Island, Hainan province, China & Bin Yang; Yonghong Liu * & [78] \\
\hline S. leptoclados & Cultured, Taiwan & Tsung-Chang Tsai; Yun-Sheng Lin * & [79] \\
\hline S. maxima & Nha Trang Bay, Vietnam & Nguyen Phuong Thao; Young Ho Kim * & [13] \\
\hline S. polydactyla & Red Sea, Hurghada, Egyptian & Mohamed Shaaban * & [80] \\
\hline S. kavarattiensis & Mandapam, Tamilnadu, India & Singanaboina Rajaram; Suryakiran Navath * & [81] \\
\hline S. dissecta & Hai Van-Son Cha, Hue, Vietnam & Nguyen Phuong Thao; Young Ho Kim * & [82] \\
\hline S. depressa & Lingshui Bay, Hainan, China & Lin-Fu Liang; Yue-Wei Guo * & [83] \\
\hline S. rigida & Sanya Bay, Hainan Island of China & Daowan Lai; Wenhan Lin * & [14] \\
\hline S. brassica & Cultured, Taiwan & Chiung-Yao Huang; Jyh-Horng Sheu * & [84] \\
\hline S. flexibilis & Sansiantai, Taitung County, Taiwan & Li-Chung Hu; Ping-Jyun Sung * & [85] \\
\hline S. candidula & Egyptian Red Sea & Safwat Ahmed * & [86] \\
\hline S. polydactyla & the Red Sea & El-Sayed A. Aboutabl; Ahmed A. Hussein * & [87] \\
\hline S. crassa & West Island, the South China Sea & Meng-Jun Wu; Yue-Wei Guo * & [88] \\
\hline
\end{tabular}

${ }^{*}$ corresponding author.

\section{Chemistry and Bioactivity of Secondary Metabolites from Genus Sinularia}

Genus Sinularia is one of the most widely distributed soft coral genera over the oceans. Many of them were chemically investigated. Especially Sinularia collected from the South China Sea, Taiwan, Vietnam, and Malaysia have provided diverse structures in recent years $[4,36,38,59]$. On the investigations of the chemical constituents from marine soft coral genus Sinularia, about 100 research papers have been published, and about 249 new compounds have been isolated and identified from more than 30 species in recent years, such as S. brassica, S. depressa, S. erecta, S. flexibilis, S. humilis, S. kavarattiensis, S. leptoclados, S. nanolobata, S. polydactyla, S. scabra, and other unidentified S. sp. (Table 1). Terpenoids and steroids/steroidal glycosides are the prominent metabolites in $S$. sp. Terpenoids from the genus Sinularia could be classified into sesquiterpenoids, diterpenes, norsesquiterpenes, norditerpenes, etc. (Scheme 1). Steroids/steroidal glycosides are mainly composed of 
normal steroids and seco-steroids. Marine-derived terpenoids have attracted the interest of natural product chemists around the world, leading to the discovery of structurally diverse metabolites, featuring many novel scaffolds equipped with a diverse array of functionality. Especially, some microbial origin terpenoids from sponges and tunicates were characterized by rare and unprecedented structures and biological activities [89,90].

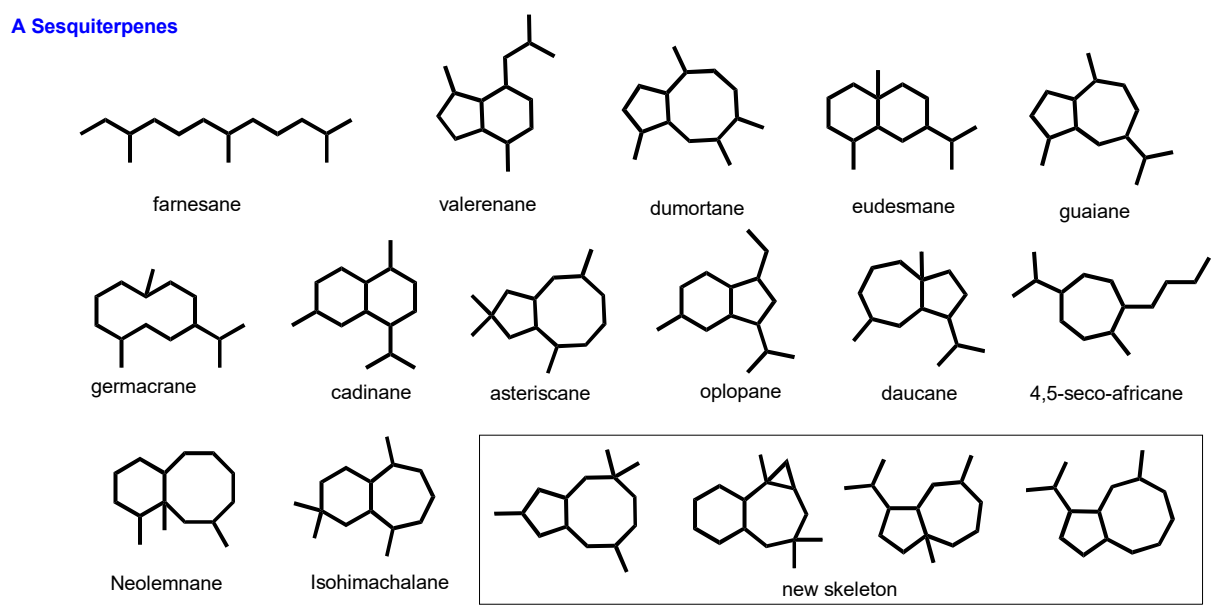

B Diterpenes

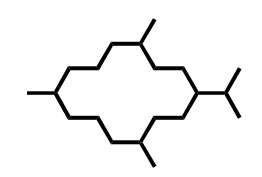

cembrane

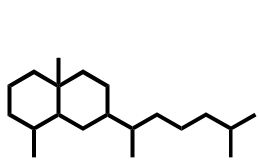

prenyleudesmane

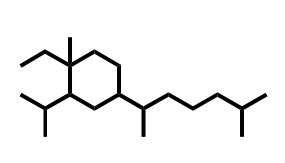

lobane

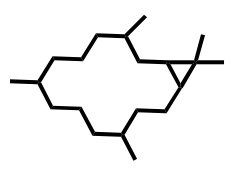

casbane

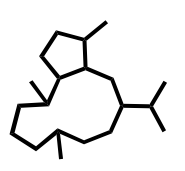

capnosane

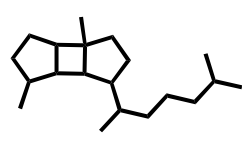

spatane

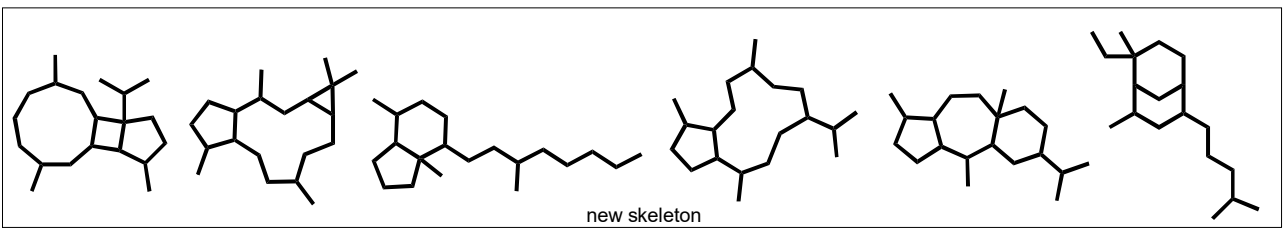

C Norterpenoid

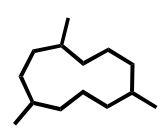

norhumulene

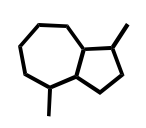

de-isopropyl guaiane

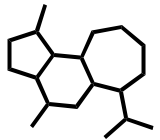

normandapamatan

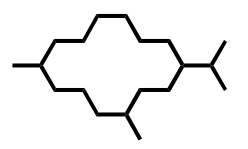

norcembranoid

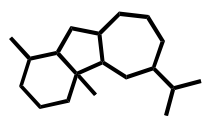

sinulanorcembrane

Scheme 1. Various carbon skeletons of terpenoids from soft coral of genus Sinularia since 2013.

\subsection{Terpenoids}

\subsubsection{Sesquiterpenes and Bioactivities}

A farnesyl diphosphate (FPP, C15) is regarded as the same biosynthetic precursor of sesquiterpene. Sesquiterpenes from $S$. sp. include chain and ring structures. The 
ring structures are formed from one or more cyclizations of FPP by FPP cyclase. Various carbocation intermediates formed after cyclization may need further cyclization, hydrogen anion migration, methyl transfer, or Wagner-Meerwein rearrangement to remove protons or absorb protons to form the final products. In recent years, about 35 new sesquiterpenes (Figure 2) have been isolated from the genus Sinularia. According to the carbon skeletons, it can be classified into 17 types, including four new carbon skeletons. (Figure 1). Various activities about these new sesquiterpenes, such as cytotoxicity [78], anti-inflammatory [76], antimicrobial [51], and antimalarial [10], were reported (Table 2).
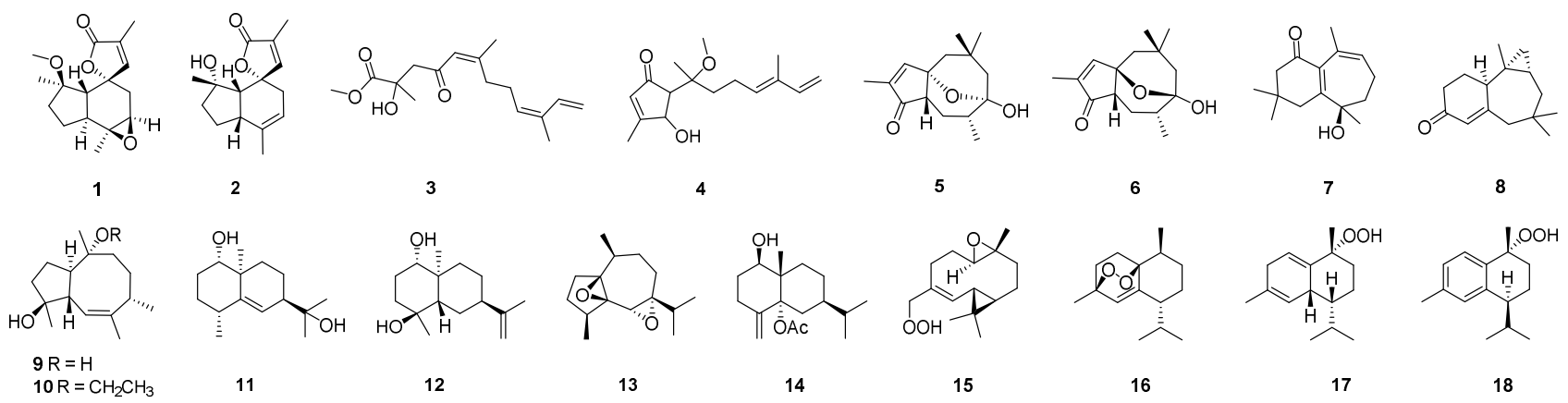

4

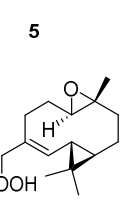

15

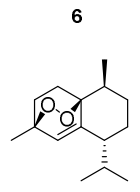

16

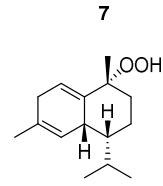

17

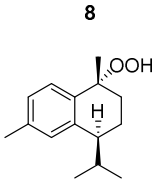

18

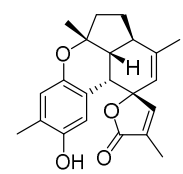

19

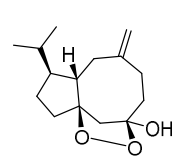

28<smiles>CC1CC(C)C(C)CC1C</smiles>

20

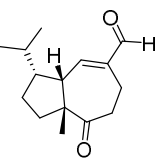

29<smiles>CC1CCC2(O)CCCCC12O</smiles>

21

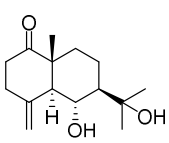

30

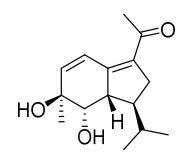

22

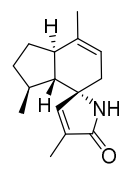

31<smiles>CC(=O)CCC1CC(C)CCC1CO</smiles>

23

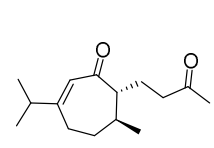

24

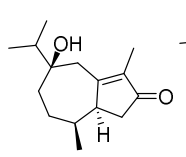

25

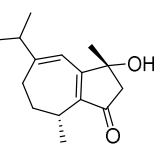

26

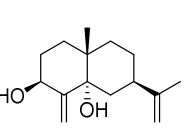

27

Figure 2. Sesquiterpenes isolated from the genus Sinularia.

Table 2. Biological activities of new sesquiterpenes from genus Sinularia.

\begin{tabular}{|c|c|c|c|c|}
\hline Drug Class & Compounds & Pharmacology & Activities & Ref. \\
\hline \multirow[t]{5}{*}{ Anti-inflammatory } & sinularianins C-F (1-4) & NF- $\kappa \mathrm{B}$ inhibition & $\begin{array}{l}\text { inhibition rate: } 24.3-43.0 \% \text {, } \\
\qquad 10 \mu \mathrm{g} / \mathrm{mL}\end{array}$ & [78] \\
\hline & capillosananes W (9) & TNF- $\alpha$ inhibition & inhibition rate: $34 \%, 10 \mu \mathrm{M}$ & [76] \\
\hline & sinulatumolin A (32) & TNF- $\alpha$ inhibition & $\mathrm{IC}_{50}: 7.5 \mu \mathrm{M}$ & [8] \\
\hline & sinulatumolin C (33) & TNF- $\alpha$ inhibition & $\mathrm{IC}_{50}: 2.6 \mu \mathrm{M}$ & [8] \\
\hline & sinulatumolin D (34) & TNF- $\alpha$ inhibition & $\mathrm{IC}_{50}: 3.6 \mu \mathrm{M}$ & [8] \\
\hline \multirow[t]{3}{*}{ Antibacterial } & 13 & against Staphylococcus aureus & MIC: $18.75 \mu \mathrm{g} / \mathrm{mL}$ & [70] \\
\hline & $16-18$ & $\begin{array}{c}\text { against Staphylococcus aureus and } \\
\text { Salmonella enteric }\end{array}$ & $<12 \mathrm{~mm}^{\mathrm{a}}, 25 \mu \mathrm{g} / \mathrm{disc}$ & [51] \\
\hline & 17,18 & against Serratia marcescens & $<14 \mathrm{~mm}^{\mathrm{a}}, 26 \mu \mathrm{g} / \mathrm{disc}$ & [51] \\
\hline \multirow[t]{3}{*}{ Cytotoxicity } & $16-18$ & against HCT 116 & $\mathrm{IC}_{50}: 43.6-75.34 \mu \mathrm{M}$ & [51] \\
\hline & 27 & against A549 & $\mathrm{IC}_{50}: 14.79 \pm 0.91 \mu \mathrm{M}$ & [38] \\
\hline & sinuketal (28) & against Jurkat, MDA-MB-231, U2OS & $\mathrm{IC}_{50}: 24.9,32.3,41.7 \mu \mathrm{M}$ & [10] \\
\hline Antimalarial & sinuketal (28) & against Plasmodium falciparum 3D7 & $\mathrm{IC}_{50}: 80 \mu \mathrm{M}$ & [10] \\
\hline Antidiabetic & molestin C (26) & PTP1B inhibition & $\mathrm{IC}_{50}: 218 \mu \mathrm{M}$ & [40] \\
\hline
\end{tabular}

Four new sesquiterpenes, sinularianins C-F (1-4), were separated from a South China Sea soft coral S. sp. [78]. 1 and $\mathbf{2}$ were valerenane-type sesquiterpenes, and $\mathbf{3}$ and $\mathbf{4}$ were farnesane-type sesquiterpenes. Although compounds 3 and 4 displayed a quite different 
skeleton from that of $\mathbf{1}$ and 2, they are related to each other. From a biosynthetic aspect, sinularinins C-D (1-2), and F (4) could be generated from sinularinin E (3) via different reaction cascades [78], including dehydration, Diels Alder cyclization, Michael addition, epoxidation and dehydration, and aldol condensation.

Chemical examination of the soft coral S. capillosa from the Sanya Bay resulted in the isolation of eight new sesquiterpenoids named capillosananes S-Z (5-12) [76]. The $C D$ effects and Mosher method were determined for the assignment of their absolute configurations. Capillosananes S-U (5-7) presented as the novel carbon skeletons with bicyclo[3.6.0] and bicyclo[4.5.0] systems, while capillosanane V (8) was characteristic of an unprecedented tricyclic skeleton [76]. Capillosananes $\mathrm{W}-\mathrm{X}(\mathbf{9}, \mathbf{1 0})$ were assigned to the unusual dumortane-type sesquiterpenes, and capillosananes $Y-Z(\mathbf{1 1}, \mathbf{1 2})$ were eudesmane-type sesquiterpenes. It was the first report of dumortane analogues from marine organisms [76].

A new guaiane sesquiterpene (13) was isolated from the soft coral S. kavarattiensis, which was collected from the Mandapam coast of the Indian Ocean [70]. The relative stereochemistry of the methyl group and epoxy groups in compound $\mathbf{1 3}$ was confirmed in search of the most stable conformer of sesquiterpenoid by molecular mechanics (UFF) and density functional theory calculations, in addition to NOESY correlations [70].

A new eudesmane sesquiterpenoid $5 \alpha$-acetoxy-4(14)eudesmene- $1 \beta$-ol (14) was isolated from the octocoral S. gaweli [64].

Three cadinane-type sesquiterpenoids, endoperoxide (16) and hydroperoxides (17, 18), were obtained from an Okinawan soft coral of the Sinularia species [51]. The biogenetic pathways of 16, 17 were proposed. By a first cyclization, a 1,3-hydride shift, a second cyclization, and then deprotonation, $\delta$-Cadinene was formed from farnesyl pyrophosphate [51]. $\delta$-Cadinene gave cadinane-type endoperoxy and hydroperoxy sesquiterpenoids 16, 17 through a 1,3-hydride shift, and/or deprotonation and a reaction with singlet oxygen (Diels-Alder reaction or ene reaction) [51].

An unprecedented highly fused benzosesquiterpenoid verrubenzospirolactone (19) and a new asteriscane-type sesquiterpenoid 10-deoxocapillosanane D (20) were isolated from a South China Sea collection of the soft coral S. verruca [49]. Compound 19 was a novel skeleton that could be derived from capillobenzopyranol via a series of oxidation and cyclization reactions [49].

A new cadinane-type sesquiterpene and a new oplopane-type sesquiterpene, nanolobatols A and B (21 and 22), were isolated from the Vietnamese soft coral S. nanolobata [44].

Two 4,5-seco-africane-type sesquiterpenes, molestin A (23) and epi-gibberodione (24), and two guaiane-type sesquiterpenes, molestins B-C $(25,26)$, were isolated from the Paracel Islands soft coral S. cf. molesta [40]. Compound $\mathbf{2 6}$ displayed strong inhibitory activities against PTP1B [40].

A new eudesmane sesquiterpenoid $3 \beta, 5 \alpha$-dihydroxyeudesma-4(15),11-diene (27) was isolated from the metabolites of a Vietnamese soft coral S. erecta [38]. It exhibited selective cytotoxicity against the A549 cell line [38].

Three new sesquiterpenoids, sinuketal (28) and sinulins A and B (29 and 30), were isolated from the Xisha soft coral $S$. sp [10]. Compound 28 was the first example of marine-originated isopropyl branche undecane sesquiterpenoid, which possessed an unprecedented a bicyclo[6.3.0] undecane carbon skeleton with unique endoperoxide moiety, and compound $\mathbf{3 0}$ was a eudesmane sesquiterpenoid [10]. The relative configuration of 28 was established by a nuclear Overhauser effect spectroscopy (NOESY) experiment in combination with conformational analysis and computational approaches such as the density functional theory-NMR (DFT-NMR) method. The endoperoxide group should be on the same side of the cyclooctane ring, owing to unfavorable distortions on the basis of molecular model analysis [10].

A novel aza-spirocyclic valerenane sesquiterpenoid sinulaspirolactam A (31) was isolated from the soft coral $S$. sp. [31]. It was the first example of valerenane sesquiterpenoid bearing an aza-spiro[4.5] ring moiety [31]. The biogenetic pathway of 31 could 
be plausibly proposed. It was originated from the successive condensation of IPP and DMAPP. Valerendiene synthase (VoVDS) and then catalyzed by the cyclization of FPP into an intermediate, which underwent a series of subsequent conversions, including oxidation, double bond migration, addition, amination, and dehydration to generate 31 [31]. The cytotoxic activities were evaluated against SW480, MCF-7, HepG2, HeLa, and PANC-1 cell lines. However, $\mathbf{3 1}$ showed no obvious activity [31].

Three farnesane sesquiterpenoids sinulatumolin A-C (32-34) and a new neolemnane sinulatumolin E (35) were isolated from the South China Sea soft coral S. tumulosa [8]. Sinulatumolin A (32) represented the first example of sesquiterpene bearing an eight-membered cyclic peroxide ring from soft coral, and 34 represented the second furanosesquiterpenoid with a 2-methylfuran-3(2H)-one moiety [8]. Compounds 32, 34, and 35 displayed significant TNF- $\alpha$ inhibitory activity [8].

The bioactivities of new sesquiterpenes discovered from $S$. sp. were summarized in Table 2. It is revealed that sesquiterpene showed no significant cytotoxicity, but some of them have promising anti-inflammatory activity. These sesquiterpenes with the hydroperoxyl group showed attractive structures and a diversity of biological activities, such as anti-inflammatory activities (compounds 16-18 and 32) and antimalarial activities compound 28). As for compound 15 , no activity screening was performed.

\subsubsection{Diterpenes}

Diterpenes are synthesized by four isoprene units, and their basic structure starts with geranylgeranyl-PP (GGPP, C20). GGPP turns into a highly active carbocation intermediate catalyzed by diterpene synthase, which induced a series of cyclization reactions to form diterpenoid skeletons. The diterpenoid intermediate modified by secondary enzymatic reactions, such as hydroxylation, peroxidation, methylation, acylation, or lytic rearrangement, to produce a final product with more structural diversity and biological activity. About 109 diterpenes with different structures belonging to different chemical classes were reported from the Sinularia species in the past 8 years (Figure 3). In accordance with sesquiterpenes in this genus, the structures of diterpenoids are also variable, which could be categorized as many types [1], such as cembrane-type, casbane-type, lobane-type, and other types, including some new carbon skeletons. Among them, the cembrane-type diterpenoid has the most diverse structural variations with a multitude of functional groups (lactone, epoxide, furan, ester, aldehyde, hydroxyl, carboxyl moieties) and cyclizations [18], which could be classified into many subtypes, such as isopropyl cembranes, isopropenyl cembranes, cembranolides (5/6/7-membered lactone), furanocembranoids, and biscembranoids. Diterpenoids have been reported to display a variety of biological activities, including anti-inflammatory activity [85], cytotoxicity [72], antifouling activity against bryozoan and barnacle [14], antimicrobial activity [53], PTP1B inhibitory activity [34], anti-A $\beta$ aggregation activity [32], $\alpha$-glucosidase inhibitory activity [88], and so on.

A new cembranoidal diterpene flexibilin D (36) with a 6-membered lactone ring was isolated from the Taiwan soft coral S. flexibilis [85]. It was found to significantly inhibit the accumulation of the pro-inflammatory iNOS and COX-2 proteins of the lipopolysaccharide (LPS)-stimulated RAW264.7 macrophage cells [85].

Twelve new cembranoids sinulariols $\mathrm{T}-\mathrm{Z}_{4}(37-47)$ and a new capnosane diterpene sinulariol $Z_{5}$ (48) were separated from S. rigida [14], which was collected in Sanya Bay, Hainan Island of China. Compound $\mathbf{4 3}$ displayed dose-dependency and showed significant inhibition against the larval settlement of the barnacle $B a$. amphitrite and moderate inhibition against $B u$. neritina [14]. In addition, compound $\mathbf{4 3}$ showed a high therapeutic ratio for the inhibition of Ba. amphitrite [14].

Spatane diterpenoids are characterized by a unique tricyclic [5.3.0.0 ${ }^{26}$ ] decane ring [91]. A new spatane diterpenoid, leptoclalin A (49), was isolated from a cultured soft coral S. leptoclados [79]. A computer-modeled 3D structure of $\mathbf{4 9}$ was generated, and MM2 forcefield calculations produced the energy minimization, which was compatible with the NOE 
correlations. Compound 49 was found to show weak cytotoxicity toward the growth of T-47D and K-562 (human chronic myelogenous leukemia) tumor cells [79].

The casbanes are a small group of diterpenoids strictly related to the cembrane skeleton and characterized by the presence of a dimethyl-cyclopropyl moiety fused to the 14membered ring [77]. Six new casbane diterpenoids, sinularcasbanes A-F (50-55) were isolated from a South China Sea S. sp. soft coral [77]. These compounds were tested for cytotoxicity against a panel of tumor cell lines, but they showed no cytotoxic activity [77]. Compounds 51 and $\mathbf{5 4}$ showed moderate inhibition against lipopolysaccharide (LPS)induced nitric oxide $(\mathrm{NO})$ production [77].

Two novel diterpenoids, sinularbols A (56) and B (57) with a novel sinularboranetype carbon skeleton (3,9-cyclized cembranoid), were isolated from the Taiwan soft coral S. arborea [75]. The relative configuration of $\mathbf{5 6}$ was elucidated from the NOESY experiment and was found to be compatible with the computer modeling results. Compound 57 displayed a moderate inhibitory effect on the generation of superoxide anion [75].

One novel nine-membered macrocyclic polysulfur cembranoid lactone, sinulariaoid A (59); and three new multioxygenated cembranoids, sinulariaoid B (60), sinulariaoid C (61), and sinulariaoid D (62), were isolated from the soft coral S. sp. [72], which was collected off of Sanya Bay in the South China Sea. The absolute stereochemical structure of sinulariaoid A (59) was elucidated by single crystal X-ray diffraction analysis, and it was the first reported nine-membered macrocyclic polysulfur cembranoid from soft coral [72]. The cembranoid carbon skeleton is a logical biosynthetic precursor, and it yields many types of cembrane diterpenoid lactones via lactonization, hydrogenation, ring-opening reaction, methyl esterification, oxidation, acid-catalyzed hydrolysis, and so on [72]. The GSH was speculated to be the sulfur donor, and a CYP450 monooxygenase and glutathione S-transferase (GST) play a key role in gliotoxin C-S bond formation [72]. 59 was shown to be cytotoxic toward some cancer cell lines.

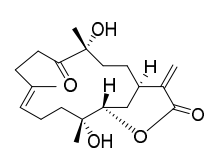

36
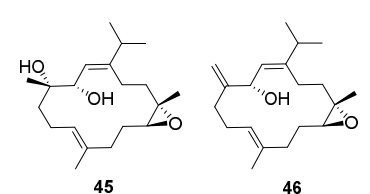

46
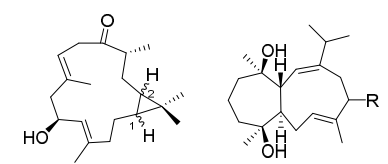

$541 \beta-H, 2 \beta-H$
$551 \beta-H, 2 \alpha-H$

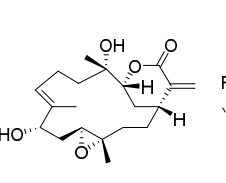

$56 \mathrm{R}=\mathrm{\beta}-\mathrm{OH}$
$57 \mathrm{R}=\mathrm{H}$

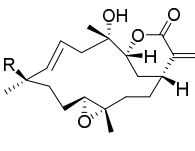

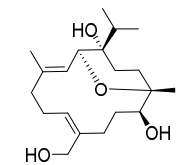
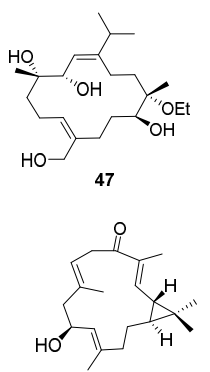

$65 \mathrm{R}=\mathrm{OOH}$
$66 \mathrm{R}=\mathrm{OH}$
38

58

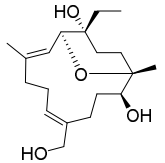

39

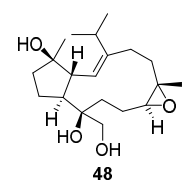

48

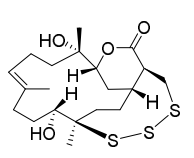

59
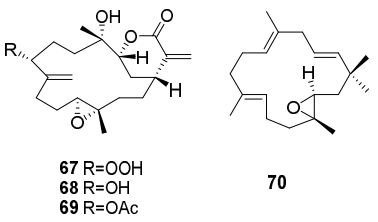

70

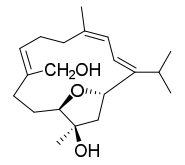

40

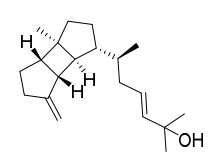

49

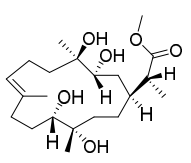

60

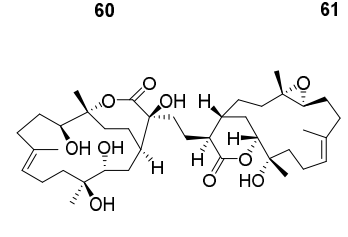

71

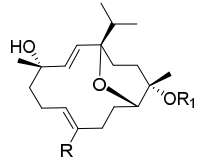

$41 \mathrm{R}=\mathrm{Me}, \mathrm{R} 1=\mathrm{H}$ $42 \mathrm{R}=\mathrm{CH}+\mathrm{OH}$ R1 $=\mathrm{Et}$
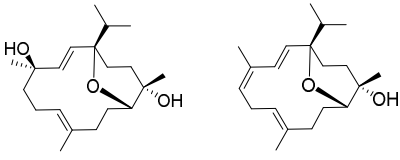

43

44

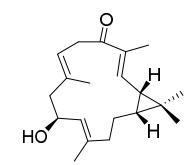

50

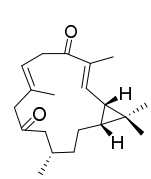

51

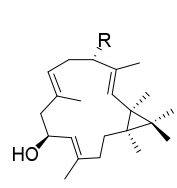

$52 \mathrm{R}=\mathrm{OH}$
$53 \mathrm{R}=\mathrm{H}$
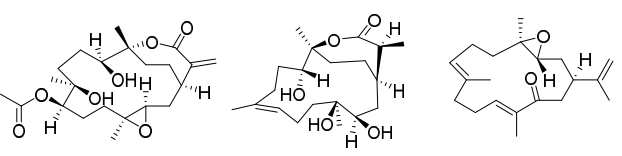

61

62

63

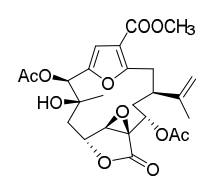

72

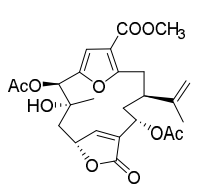

73

Figure 3. Cont. 
(1) (n)

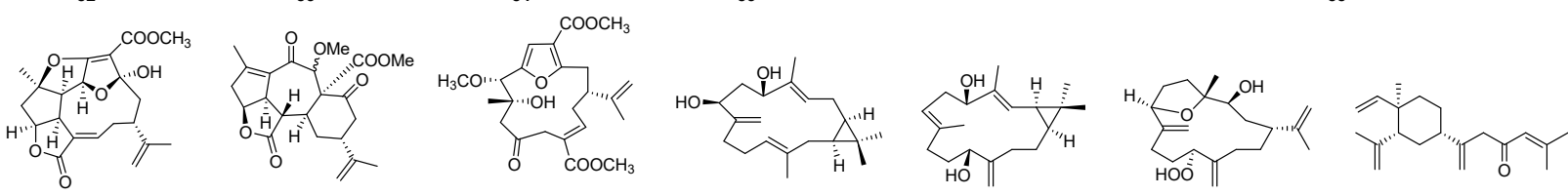
90 93 $94 \quad 95$

96 97

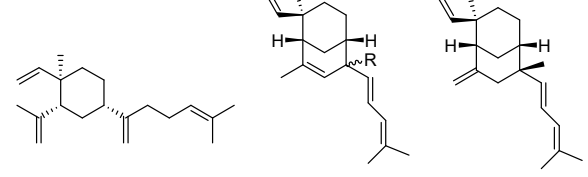

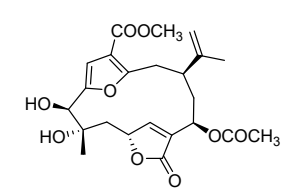

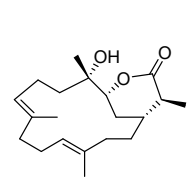

98 $99 \mathrm{R}=\alpha-\mathrm{CH}_{3}$
$100 \mathrm{R}=\beta-\mathrm{CH}_{3}$ 102

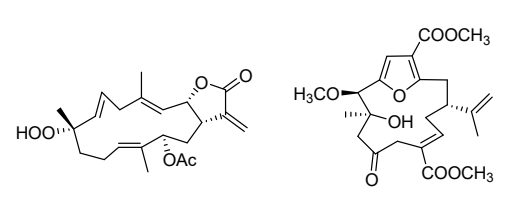
$\underbrace{n_{0}}_{0}=0$

106 107

108

109

110 111

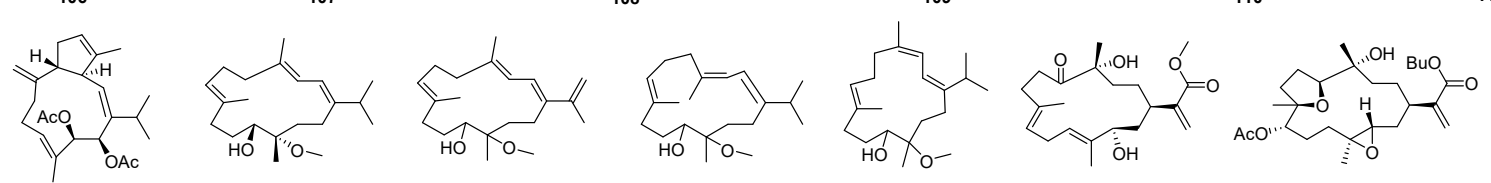

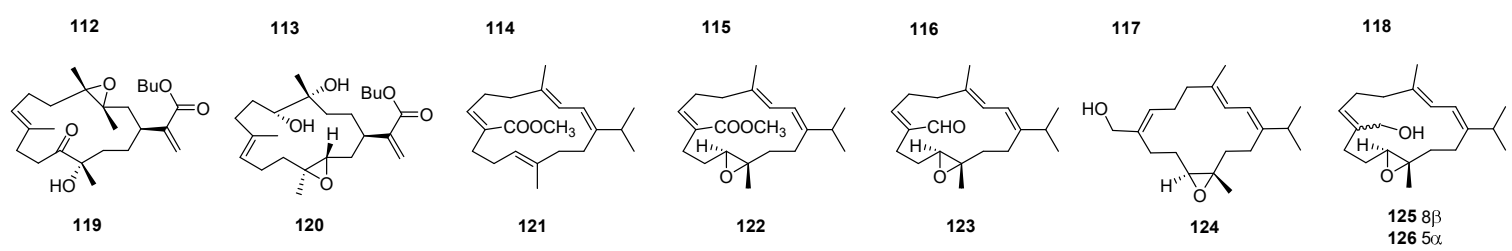

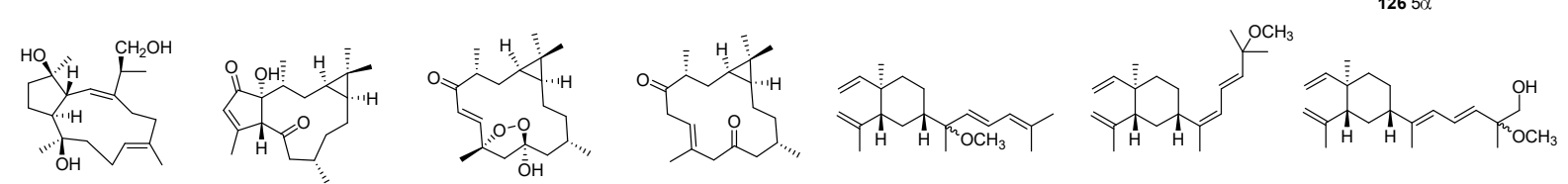

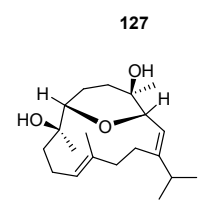

134<smiles>C=CC(C/C=C(/C)CCC(C)C)C/C=C(/C)CCC(C)O</smiles>

135

129

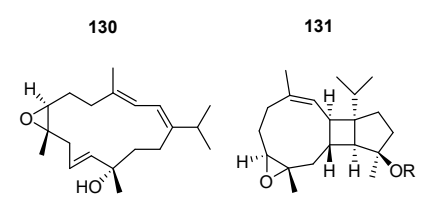

137

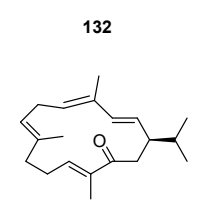

140
133

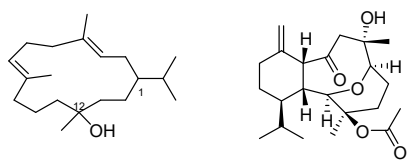

$1421 S, 12 S$
$1431 S, 12 R$
144

Figure 3. Diterpenoids isolated from the genus Sinularia. 
A new cembrane-type diterpenoid, arbolide C (63), was obtained from the Taiwan soft coral [69], and it was found to display in vitro anti-inflammatory activities with an inhibitory effect on the release of elastase by human neutrophils [69].

Eight new terpenoids, including six $\alpha$-methylene- $\delta$-lactone-bearing cembranoids (64-69), a flexitilane-type diterpenoid (70), and a biscembranoid (71), were isolated from the South China Sea soft coral S. flexibilis [65]. The structure of $\mathbf{7 1}$ was confirmed by X-ray diffraction analyses. Epoxyfexibilene (70) represents the second 15-membered macrocyclic diterpenoid being discovered from marine sources, and sinulafexiolide L (71) is the third member of the rare cembrane dimers connected through a $\mathrm{C}-\mathrm{C}$ single bond [65].

Two new rare C-7, C-8 vicinal diol-based cembrane diterpenoids, (-)-leptodiol acetate (72) and sinulacembranolide A (73), were isolated from the Taiwan soft coral S. gaweli [64]. Compound $\mathbf{7 3}$ was found to significantly reduce the levels of iNOS with no cytotoxicity to RAW264.7 macrophage cells [64].

New cembranoids 4-carbomethoxyl-10-epigyrosanoldie E (74) 7-acetylsinumaximol B (75) diepoxycembrene B (76), dihydromanaarenolide I (77), and isosinulaflexiolide K (78) were isolated from cultured soft corals $S$. sandensis and S. flexibilis [63]. The absolute configurations of $\mathbf{7 4}$ and $\mathbf{7 8}$ were further confirmed by single-crystal X-ray diffraction analysis. It should be noticed that the hypothesis (that cembrane diterpenes possessing an absolute configuration of an isopropyl group at $\mathrm{C} 1$ obtained from Alcyonacean soft corals belong to the $\alpha$ series, whereas analogues isolated from Gorgonacean corals belong to the $\beta$ series) is not applicable for a small number of cembranoids. Compound 78 was found to significantly reduce the levels of iNOS and COX-2 [63]. It was proposed that the presence of one seven-membered lactone functional group was critical for antiinflammatory activity [63].

Six new casbane diterpenoids, sinularcasbanes G-L (79-84), were separated from the soft coral S. sp. [62], which was collected from Dongluo Island, Hainan Province of China. However, these compounds showed no cytotoxicity against ten human cancer cell lines (H1975, U937, K562, BGC823, MOLT-4, MCF-7, A549, HeLa, HL60, and Huh-7).

Two new cubitane-type diterpenoids, nanoculones A and B (85 and 86) and three new cembranoids, nanolobols A-C (87-89), were isolated from Taiwan soft coral S. nanolobata [59]. Compound 86 could effectively reduce the levels of LPS-stimulated NO production in activated RAW264.7 cells. These compounds were not cytotoxic against P388, K562, and HT-29 cell lines [59]. Considering their prior work on the same species collected in different locations of Taiwan water, it is noteworthy that the metabolites from soft corals, even the skeletons, might vary with their geographical location [59].

Four new diterpenoids, pambanolides A-C (90-93), were isolated from the soft coral S. inelegans [58], which was collected in the Gulf of Mannar on the southern coast of India. A biosynthetic pathway has been proposed for the formation of pambanolides A (90). It could be obtained from the precursor metabolite mandapamate, via oxa-Michael addition and intramolecular rearrangement [58]. Compounds $\mathbf{9 1}$ and 92 showed weak activity against the DU145 and A549 cancer cell lines [58].

A solvent extract of $S$. polydactyla resulted in the isolation of two new casbane diterpenes: sinularcasbane $\mathrm{M}(\mathbf{9 4})$ and sinularcasbane N (95). Compounds were elucidated based on spectroscopic analyses; the absolute configuration was confirmed by X-ray analysis [57].

A cembranoid sinulerectol C (96) with a hydroperoxy group was separated from soft coral S. erecta [3], which was collected off the coast of Dongsha Atoll. Compound 96 showed cytotoxicity toward the K-562 cell line. Moreover, it exhibited potent inhibitory activity against elastase release [3].

Two new lobane diterpenoids, prenyl- $\alpha$-elemenone (97) and ent-prenyl- $\beta$-elemene (98), were obtained from Bornean soft coral S. sp. [53]. Cytotoxicity assays against B16-F10 and HT-29 cells displayed no activity. However, compound 97 exhibited inhibition against S. aureus [53]. 
Three new diterpenes with a new carbon skeleton, xishacorenes $A-C$ (99-101), featuring an undescribed bicyclo[3.3.1]nonane nucleus bearing 1-vinyl and 13-[(E)-4-methylpenta1,3-dien-1-yl] alkyl chains were isolated from the Xisha soft coral S. polydactyla [41]. The new skeleton was structurally related with lobane-type diterpenes by sharing some common moieties, such as the cyclohexane ring bearing a vinyl group and a conjugated diene side chain [41]. The research team proposed that an electron delivery from the $\Delta^{10 / 12}$ olefinic head to the activated hydroxyl tail accomplished the cyclization of a six-member ring [41]. These three compounds were found to promote the ConA-induced T lymphocytes proliferation with dose-dependency and had no activity on LPS induced B lymphocytes proliferation.

A new furanocembranolide molestin E (102) was isolated from the Paracel Islands soft coral S. cf. molesta [40], and it exhibited cytotoxicities against HeLa and HCT-116 cell lines [40].

A new cembrane ent-sinuflexibilin D (103) was isolated from a Bornean soft coral S. flexibilis [37]. Compound 103 showed cytotoxicity against the S1T cell line [37].

A new cembranoid sinularolide F (104) was isolated from the Bornean soft coral S. sp. [36]. It showed potential anti-inflammatory activities against lipopolysaccharidestimulated RAW 264.7 through inhibiting NO synthesis by reducing the expression of iNOS protein. In addition, compound 104 exhibited apoptosis activity against HL-60 cells. The expressions of apoptotic proteins suggested that 104 triggered the up-regulation of Bax, the downregulation of Bcl-xL, and the activation of caspase-3 in the apoptosis mechanism [36].

Five new cembranoid-related diterpenoids, flexibilisins D and E (106 and 107), secoflexibilisolides A and B (108 and 109), and flexibilisolide H (110) were obtained from Taiwan soft coral S. flexibilis [35]. Compound $\mathbf{1 0 8}$ possessed an unusual skeleton that could be biogenetically derived from cembranoid flexibilisolide $D$, which is a known compound that was also isolated from this coral. After oxidative cleavage, Michael addition, condensation, rearrangement, and reduction, flexibilisolide $\mathrm{D}$ could be converted to secoflexibilisolide A. Compound 109 could be derived from sinuflexolide via oxidative cleavage of the diol groups, epimerization of the vinyl alcohol, and subsequent esterification. These compounds were nontoxic toward cancer cell lines P-388, K-562, and HT-29 [35].

A new prenyleudesmane type diterpene sinupol (111) and a new capnosane type diterpenoid sinulacetate (112) were isolated from the Xisha soft coral S. polydactyla [34]. The time-dependent density functional theory electronic circular dichroism (TDDFT ECD) calculation was applied to establish their absolute configurations [34]. Compound 111 was proposed to be a cyclization product of fuscol, and a capnosane diterpenoid, sinulacetate (112), with 5:11-fused carbobicyclic skeleton, could be derived from the cembranoid [34]. These two new compounds exhibited promising inhibitory activity against protein tyrosine phosphatase 1B (PTP1B) [34].

Four new cembranoids (113-116) were isolated from the South China Sea soft coral $S$. sp. [32]. The absolute configuration of $\mathbf{1 1 3}$ was established by X-ray diffraction analysis. Compounds 113 and 115 displayed moderate inhibitory activity against $A \beta_{42}$ aggregation [32]. The binding mode of 113 with $A \beta_{42}$ monomer was predicted by molecular docking. In addition, compounds 113-115 did not show cytotoxicity against human tumor cell lines (SH-SY5Y, MDA-MB-426, A549, Hep3B, and HT-29) [32].

A new cembrane-type diterpenoid, sinulaflexiolide $\mathrm{P}$ (117), was isolated from a Bornean soft coral S. flexibilis [29]. It was screened against six fungal strains: Fusarium moniliforme (NJM 8995), F. oxysporum (NJM 0179), F. solani (NJM 8996), Haliphthoros milfordensis (IPMB 1603), H. sabahensis (IPMB 1402), and Lagenidium thermophilum (IPMB 1401). It exhibited promising inhibitory activity against $H$. sabahensis, L. thermophilum, and H. milfordensis [29].

Three novel cembranoid esters xidaosinularide A-C (118-120) featuring an n-butyl alcohol moiety were obtained from Hainan soft coral S. flexibilis [27]. Compound 118 reduced the levels of TNF- $\alpha$ in lipopolysaccharide (LPS)-stimulated RAW 264.7 cells [27]. 
Six new cembrane type diterpenoids xiguscabrates A and B (121 and 122), xiguscabral A (123), xiguscabrols A and B (124 and 125), and 8-epi-xiguscabrol B (126) were isolated from the South China Sea soft coral S. scabra [26]. Compounds $\mathbf{1 2 2}$ and 124-126 exhibited strong inhibitory activity on the proliferation of Con A-induced T lymphocyte cells [26]. It was suggested that the position and the number of hydroxyls might influence the toxicity of cembranoids, while it could not affect the immunological activity [26].

A new diterpenoid with an unusual capnosane skeleton, sinuhumilol A (127), was isolated from the South China Sea soft coral S. humilis [23]. However, it showed no obvious cytotoxicity against a series of tumor cell lines, including A549 (lung adenocarcinoma), HT-29 (colonic carcinoma), SNU-398 (hepatocellular carcinoma), and Capan-1 (pancreatic carcinoma) [23].

A novel diterpenoid, sinueretone A (128), featuring an unprecedented tricyclo pentadecane carbon framework, and two new casbane-type diterpenoids sinuereperoxide A (129) and 10-oxo-3,4,11,12-tetrahydrodepressin (130) were isolated from the South China Sea soft coral S. erecta [7]. Analysis of the X-ray data unambiguously confirmed the planar structure of $\mathbf{1 2 9}$ and the determination of its absolute configuration. Compounds 128 and 129 displayed anti-inflammatory activity of lipopolysaccharide (LPS)-induced tumor necrosis factor (TNF)- $\alpha$ protein release in RAW264.7 macrophages [7]. Compound 129 showed anti-inflammatory activity, indicating that the peroxide bridge might be helpful for the activity. Both of them exhibited no obvious cytotoxicity against RAW264.7 cells [7].

Three new lobane-type diterpenes, 13-methoxyloba-8,10,15(16),17(18)-tetraene (131), 8,10,13(15)Z,16E-lobatetraene (132), and 19-hydroxy-lobatetraene (133) were isolated from the South China Sea soft coral, but they are inactive on antibacterial, PTP1B inhibitory, and immunological activities [21].

Four new cembranoids, humilisins A-D (134-137), and two new uncommon diterpenoids humilisins $E$ and F (138 and 139) with new carbon skeletons were isolated from the South China Sea soft coral S. humilis [4]. Humilisin A (134) was the first cembranoid with an ether linkage between C-3 and C-7. Humilisins E and F (138 and 139) possessed a tetradecahydrocyclopenta[ $\left[3^{\prime}, 4^{\prime}\right]$ cyclobuta[ $\left.1^{\prime}, 2^{\prime}: 4,5\right]$ cyclonona [1,2-b]-oxirene ring system [4]. Compound 139 displayed a significant inhibitory effect on LPS-induced inflammatory response (NO production) in BV-2 microglial cells, and the level of NO decreased [4].

Four new cembranoids, sinulacrassins A-C (140-142) and ent-xishaflavalin $G$ (143), were yielded from the South China Sea soft coral S. crassa [88]. The bioassay results revealed that compound $\mathbf{1 4 1}$ was a novel $\alpha$-glucosidase inhibitor and nontoxic toward human normal hepatocyte (LO2) cells [88].

A eunicellin-based diterpenoid multifloralin (144) was isolated from the extract of the South China Sea soft coral S. multiflora [28]. It showed potent antifouling activity against barnacle Balanus albicostatus [28].

As shown in Table 3, diterpenoids from S. sp. were found to be of promising biofunctional diversities. The biological properties reported in several works were attributed to the variability of chemical structures. It could be concluded that nearly all the bioactive diterpenoids possess oxygenic rings or hydroxy groups, and the position of the oxygenic ring, as well as the position and number of hydroxyls, might influence the activities. For example, the presence of one seven-membered lactone functional group at position $\mathrm{C} 1$ is critical for the anti-inflammatory action of this class of compounds [63]. In particular, the multisulfide moiety of sinulariaoid A (59) played an important role in the cytotoxic bioactivities. The diterpenoids with a hydroperoxyl group also showed significant antiinflammatory activity or cytotoxicity. 
Table 3. Biological activities of new diterpenes from genus Sinularia.

\begin{tabular}{|c|c|c|c|c|}
\hline Drug Class & Compounds & Pharmacology & Activities & Ref \\
\hline \multirow{14}{*}{$\begin{array}{l}\text { Anti- } \\
\text { inflammatory }\end{array}$} & sinularcasbane B (51) & inhibit NO production & $\mathrm{IC}_{50}: 8.3 \mu \mathrm{M}$ & [77] \\
\hline & sinularcasbane E (54) & inhibit NO production & $\mathrm{IC}_{50}: 5.4 \mu \mathrm{M}$ & [77] \\
\hline & nanoculone B (86) & inhibit NO production & inhibition rate: $8 \%, 10 \mu \mathrm{M}$ & [59] \\
\hline & sinularolide F (104) & inhibit NO production & $\mathrm{IC}_{50}<6.25 \mu \mathrm{g} / \mathrm{mL}$ & [36] \\
\hline & humilisin F (139) & inhibit NO production & inhibition rate: $83.96 \%, 10 \mu \mathrm{M} ; 65.70 \%, 20 \mu \mathrm{M}$ & [4] \\
\hline & arbolide C (63) & inhibit release of elastase & $\mathrm{IC}_{50}: 5.13 \mu \mathrm{g} / \mathrm{mL}$ & [69] \\
\hline & sinulerectol C (96) & inhibit release of elastase & inhibition rate: $33 \%, 10 \mu \mathrm{M}$ & [3] \\
\hline & sinularbol B (57) & inhibit superoxide anion generation & inhibition rate $23.94 \%, 10 \mu \mathrm{g} / \mathrm{mL}$ & [75] \\
\hline & flexibilin D (36) & iNOS and COX-2 inhibition & inhibition rate: $19.27 \%$ and $30.08 \%, 20 \mu \mathrm{M}$ & [85] \\
\hline & isosinulaflexiolide $\mathrm{K}(\mathbf{7 8})$ & iNOS and COX-2 inhibition & inhibition rate: $30.9 \%$ and $47.1 \%, 10 \mu \mathrm{M}$ & [63] \\
\hline & sinulacembranolide A (73) & iNOS inhibition & inhibition rate: $8.55 \%, 10 \mu \mathrm{M}$ & {$[64]$} \\
\hline & xidaosinularide A (118) & TNF- $\alpha$ inhibition & $\mathrm{IC}_{50}: 38.9 \mu \mathrm{M}$ & [27] \\
\hline & sinueretone A (128) & TNF- $\alpha$ inhibition & inhibition rate: $21.9 \%, 20 \mu \mathrm{M}$ & [7] \\
\hline & sinuereperoxide A (129) & TNF- $\alpha$ inhibition & inhibition rate: $56.2 \%, 20 \mu \mathrm{M}, \mathrm{IC}_{50}: 10.6 \mu \mathrm{M}$ & [7] \\
\hline \multirow[t]{8}{*}{ Cytotoxicity } & leptoclalin A (49) & against $\mathrm{T}-47 \mathrm{D}$ and $\mathrm{K}-562$ & $\mathrm{IC}_{50:} 15.4$ and $12.8 \mu \mathrm{g} / \mathrm{mL}$ & [79] \\
\hline & sinulariaoid A (59) & $\begin{array}{c}\text { against HepG2, HepG2/ADM, MCF-7, } \\
\text { and MCF-7/ADM }\end{array}$ & $\mathrm{IC}_{50}: 15.35,9.70,18.41$ and $16.95 \mu \mathrm{M}$ & {$[72]$} \\
\hline & sinulerectol C (96) & against K-562 & $\mathrm{IC}_{50}: 9.2 \mu \mathrm{M}$ & [3] \\
\hline & pambanolides B-C (91 and 92) & against DU145 and A549 & $\mathrm{IC}_{50}: 63-55 \mathrm{mM}$ & [58] \\
\hline & xishacorenes A-C (99-101) & $\begin{array}{l}\text { promote the ConA-induced } \mathrm{T} \\
\text { lymphocytes proliferation }\end{array}$ & dose-dependency $(10-40 \mu \mathrm{M})$ & {$[41]$} \\
\hline & molestin E (102) & against HeLa and HCT-116 & $\mathrm{IC}_{50:} 5.26$ and $8.37 \mu \mathrm{M}$ & {$[40]$} \\
\hline & ent-sinuflexibilin D (103) & against $\mathrm{S} 1 \mathrm{~T}$ & $\mathrm{IC}_{50}: 5.27 \mu \mathrm{g} / \mathrm{mL}$ & [37] \\
\hline & sinularolide F (104) & against HL-60 & cell viability: $<30 \%, 25.0 \mu \mathrm{g} / \mathrm{mL}$ & [36] \\
\hline \multirow[t]{3}{*}{ Antimalarial } & sinulariol $Z_{5}(48)$ & against barnacle $B a$. amphitrite & $\mathrm{EC}_{50}: 4.57 \mu \mathrm{g} / \mathrm{mL}$ & [14] \\
\hline & & against $B u$. neritina & $\mathrm{EC}_{50}: 13.48 \mu \mathrm{g} / \mathrm{mL}$ & [14] \\
\hline & multifloralin (144) & barnacle Balanus albicostatus & adhesive rate: $0 \%$; lethal rate: $58.11 \%$, at $25 \mathrm{ppm}$ & [28] \\
\hline \multirow[t]{3}{*}{ Antidiabetic } & sinupol (111) & PTP1B inhibition & $\mathrm{IC}_{50}: 63.9 \mu \mathrm{M}$ & {$[34]$} \\
\hline & sinulacetate (112) & PTP1B inhibition & $\mathrm{IC}_{50}: 51.8 \mu \mathrm{M}$ & [34] \\
\hline & sinulacrassin (141) & $\alpha$-glucosidase inhibitor & $\mathrm{IC}_{50}: 10.65 \mu \mathrm{M}$ & [88] \\
\hline Antibacterial & prenyl- $\alpha$-elemenone (97) & against $S$. aureus & MBC: $50 \mu \mathrm{g} \mathrm{mL}^{-1} ; \mathrm{MIC}: 20 \mu \mathrm{g} \mathrm{mL}^{-1}$ & [53] \\
\hline Antifungal & sinulaflexiolide P (117) & against $H$. milfordensis & MIC: $25 \mu \mathrm{g} / \mathrm{mL}$ & [29] \\
\hline Anti-AD & 113 and 115 & inhibit $A \beta_{42}$ aggregation & inhibition rate: $20.6 \%$ and $37.2 \%$, respectively, $10 \mu \mathrm{M}$ & [32] \\
\hline \multirow[t]{4}{*}{ Immunosuppression } & xiguscabrate B (122) & $\begin{array}{l}\text { inhibit Con A-induced T lymphocyte } \\
\text { cells proliferation }\end{array}$ & $\mathrm{IC}_{50}: 8.4 \mu \mathrm{M}$ & [26] \\
\hline & xiguscabrol A (124) & $\begin{array}{l}\text { inhibit Con A-induced T lymphocyte } \\
\text { cells proliferation }\end{array}$ & $\mathrm{IC}_{50}: 5.5 \mu \mathrm{M}$ & [26] \\
\hline & xiguscabrol B (125) & $\begin{array}{l}\text { inhibit Con A-induced T lymphocyte } \\
\text { cells proliferation }\end{array}$ & $\mathrm{IC}_{50}: 3.9 \mu \mathrm{M}$ & [26] \\
\hline & 8-epi-xiguscabrol B (126) & $\begin{array}{l}\text { inhibit Con A-induced T lymphocyte } \\
\text { cells proliferation }\end{array}$ & $\mathrm{IC}_{50}: 2.3 \mu \mathrm{M}$ & [26] \\
\hline
\end{tabular}

\subsubsection{Norterpenoid}

The mechanisms leading to the occurrence of norterpenoids are not well understood, but they may include the production of anionic and radical intermediates along with competitive transannular carbon-to-carbon bond-forming reactions [18]. Norterpenoids could be commonly considered as one of the chemotaxonomic markers of soft corals of genus Sinularia. To date, several novel norsesquiterpenoids and norditerpenoids have been isolated and structurally elucidated from Sinularia species. The structures of norsesquiterpenoids could be variable as sesquiterpenoids, but there were not many reported. Up until now, about 10 norsesquiterpenoids were obtained from $S$. sp.; to the best of our knowledge, three of them were found since 2013 (Figure 4). Two were uncommon norhumulene-type norsesquiterpenoids sinuhirtins A (145) and B (146), which were isolated from the South China Sea soft coral S. hirta [30]. The norhumulene was suggested to be the precursor. Molestins D (147) was the first example of a norsesquiterpene with a de-isopropyl guaiane skeleton isolated from the genus Sinularia [40], and it showed significant inhibitory activities against protein tyrosine phosphatase 1B (PTP1B). 


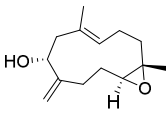

145

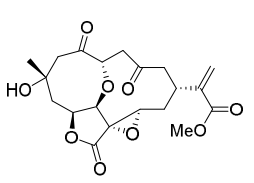

152

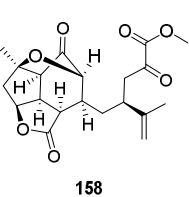

158

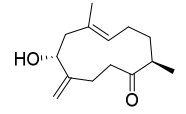

146

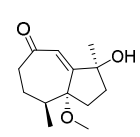

147

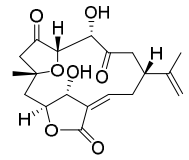

148

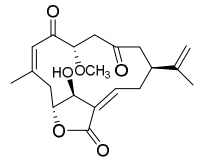

149

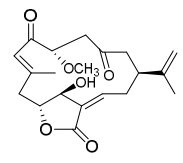

150

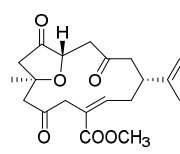

156

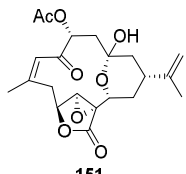

151

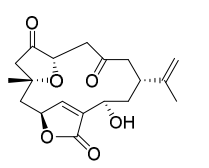

154

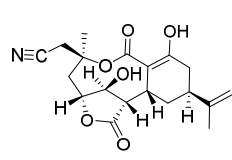

155

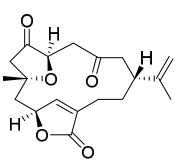

157

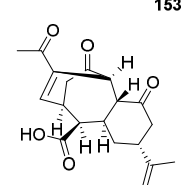

159

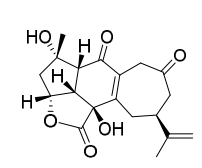

160

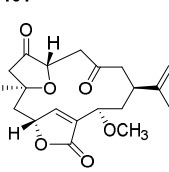

161

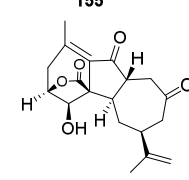

162

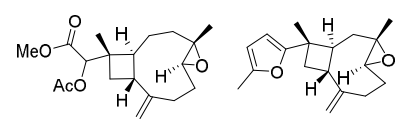

163

164

Figure 4. Norterpenoids isolated from genus Sinularia.

The norditerpenes from $S$. sp. are relatively abundant and novel in structures. Norcembranoids are the most structurally diverse norditerpenes produced by $S$. sp. Compared with cembranoids, norcembranoids are those that lack a C-18 carbon substituent on C-4 [1] and always have a furane heterocycle. They are a rich source of bioactive substances with intriguing and unique structural features (Figure 4). Other types of norditerpenes such as sinulariane-type, horane-type, normandapamatane-type, and sinulanorcembrane-type were also reported in recent years [13,28,71,85].

A new 4-norcembranoidal diterpene possessing a $\gamma$-lactone ring, $4 \alpha$-hydroxy-5episinuleptolide (148) was isolated from a cultured soft coral S. numerosa [66]. Cytotoxicity toward CCRF-CEM (human acute lymphoblastic leukemia), HL-60, K-562, U-937 (human histiocytic lymphoma), DLD-1 (human colorectal adenocarcinoma), LNCaP, and MCF7 tumor cells were studied. Compound 148 exhibited moderate cytotoxicity toward CCRF-CEM cells [66].

Two new norcembranoids, sinumerolide A (149) and its epimer, 7E-sinumerolide A (150), were isolated from the soft coral S. numerosa [61]. Norcembranoids $\mathbf{1 4 9}$ and 150 were found to inhibit the accumulation of the pro-inflammatory inducible nitric oxide synthase protein of lipopolysaccharide-stimulated RAW264.7 macrophage cells significantly [61].

Four new isoprenoids, including two norcembranoids sinulerectols A and B (151 and 152), a cembranoid sinulerectol C (96), and a degraded cembranoid sinulerectadione (153), were isolated from Dongsha Atoll soft coral S. erecta [3]. Compounds 151 and 152 exhibited strong inhibitory effects on superoxide anion generation [3]. They also exhibited potent inhibitory activity against elastase release in the fMLP/CB stimulated cells [3]. Moreover, compounds 151 and 152 were found to show potent activities in the inhibition of superoxide generation and elastase release [3]. Compound 153 exhibited cytotoxicity toward K-562 and MOLT-4 cancer cell lines [3].

One new polycyclic furanobutenolide-derived norcembranoid was isolated from xiguscabrolide H (154), from the South China Sea soft corals S. scabra [24], and it exhibited potent inhibitory activities on the proliferation of Con A-induced T lymphocyte cells and LPS-induced B lymphocyte cells [24].

A rare sinulariane-type norditerpene sinulariadiolide B (155) with a unique cyano group was isolated from the South China Sea soft coral S. multiflora [28]. The cytotoxic activities were evaluated against selected cell lines including HL-60, K562, HCT-116, A549, BEL-7402, HeLa, and L-02. All compounds were not cytotoxic toward the above seven cell lines [28]. However, 155 showed weak activity for antifouling against barnacle B. albicostatus [28].

A seco-yonarane norditerpenoid, 4,5-secosinulochmodin C (158), was isolated from the soft coral S. inelegans [58]. Compound 158 was an unprecedented skeleton with an eightcarbon side chain bearing an isopropenyl substituent and terminated by an a-keto ester 
functionality, which appears to be a C4-C5 redox bond cleavage product of sinulochmodin C [58].

A new horane-type norditerpenoid, named kavaranolide (159), was isolated from the Indian soft coral S. kavarattiensis [71]. It possessed a tricyclic carbocycle with the trans-fused six and seven-membered rings. The replicon-inhibiting potential of compound 159 was evaluated, but it showed no obvious activity [71].

A new normandapamatane-type norditerpenoid 12-hydroxy-scabrolide A (160) and a new norcembranoid 13-epi-scabrolide C (161) were obtained from the soft coral S. maxima [13]. It was confirmed that $\mathbf{1 6 1}$ had little or no effect on cell viability and potently inhibited IL-12 and IL-6 production in LPS-stimulated bone marrow derived dendritic (BMDCs). Compound $\mathbf{1 6 1}$ did not exhibit inhibitory activity on TNF- $\alpha$ production [13].

A new sinulanorcembrane-type norditerpene, 1-epi-sinulanorcembranolide A (162) was isolated from the soft corals $S$. gaweli [85]. These in vitro anti-inflammatory effects were evaluated, and it did not attenuate the iNOS and COX-2 expression in LPS-stimulated macrophage cells.

A novel tetranorditerpenoid, sinubatin A (163) (having an unprecedented carbon skeleton), and a new norditerpenoid, sinubatin B (164) (a 4,5-epoxycaryophyllene possessing an unusual methylfuran moiety side chain), were isolated from soft coral S. nanolobata [39]. The cytotoxicity of compounds 163 and 164 against mouse lymphocytic leukemia (P-388), human colon adenocarcinoma (HT-29), and human lung epithelial carcinoma (A-549) tumor cell lines were tested but showed no activity [39]. Compounds 163 and 164 were also examined for antiviral activity against human cytomegalovirus (HCMV) and did not show anti-HCMV activity [39].

As shown in Table 4, polycyclic furanobutenolide-derived norditerpenoids were reported to comprise a broad range of biological activities, such as cytotoxic, anti-inflammatory, and immunosuppression and antimalarial activities. Similar to cembranoids, oxygenic rings or hydroxy groups might be critical to the bioactivities. Other types of norditerpenoids showed intriguing structural features with novel carbon skeleton, but their biological activities still need to be explored.

Table 4. Biological activities of new norterpenoids from genus Sinularia.

\begin{tabular}{|c|c|c|c|c|}
\hline Drug Class & Compounds & Pharmacology & Activities & Ref \\
\hline \multirow[t]{5}{*}{ Anti-inflammatory } & sinumerolide A (149) & inhibit NO production & inhibition rate: $59.82 \%, 10 \mu \mathrm{M}$ & [61] \\
\hline & 7E-sinumerolide A (150) & inhibit NO production & inhibition rate: $68.40 \%, 10 \mu \mathrm{M}$ & [61] \\
\hline & sinulerectol A (151) & $\begin{array}{l}\text { inhibit superoxide anion generation } \\
\text { and release of elastase }\end{array}$ & $\mathrm{IC}_{50}: 2.3,0.9 \mu \mathrm{M}$ & {$[3]$} \\
\hline & sinulerectol B (152) & $\begin{array}{l}\text { inhibit superoxide anion generation } \\
\text { and release of elastase }\end{array}$ & $\mathrm{IC}_{50}: 8.5,3.8 \mu \mathrm{M}$ & [3] \\
\hline & 13-epi-scabrolide C (161) & inhibit IL-12 and IL-6 & $\mathrm{IC}_{50}: 5.3,13.12 \mu \mathrm{M}$ & [13] \\
\hline \multirow[t]{2}{*}{ Cytotoxicity } & $4 \alpha$-hydroxy-5-episinuleptolide (148) & against CCRF-CEM & $\mathrm{IC}_{50:} 4.21 \mu \mathrm{g} / \mathrm{mL}$ & [40] \\
\hline & sinulerectadione $(\mathbf{1 5 3})$ & against K-562 and MOLT-4 & $\mathrm{IC}_{50}: 8.6,9.7 \mu \mathrm{M}$ & [3] \\
\hline Antidiabetic & molestins D (147) & PTP1B inhibition & $\mathrm{IC}_{50}: 344 \mu \mathrm{M}$ & [40] \\
\hline Immunosuppression & xiguscabrolide H (154) & $\begin{array}{l}\text { inhibit T and B lymphocyte cells } \\
\text { proliferation }\end{array}$ & $\mathrm{IC}_{50}: 45.76,44.14 \mu \mathrm{M}$ & {$[3]$} \\
\hline Antimalarial & sinulariadiolide B (155) & against barnacle $B$. albicostatus & $\begin{array}{l}\text { adhesive rate: } 41.55 \% \text {, at } \\
25 \text { ppm }\end{array}$ & [24] \\
\hline
\end{tabular}

\subsection{Steroids/Steroidal Glycosides}

Among the various classes of secondary metabolites produced by soft corals $S$. sp., steroids come next as a major group of metabolites after terpenoids (Figure 5). The steroid is a kind of natural product with a perhydrocyclopentanophenanthrene skeleton by removing three methyl groups based on lanosterol triterpenoid skeleton. The variations of side chains, high degrees of oxygenation, and re-arrangement on the rings of the tetracyclic nucleus account for the fascinated diversity of such steroids [74]. Among them, withanolides are a group of $\mathrm{C}_{28}$ steroidal lactones possessing mostly a C-22/C-26 $\delta$-lactone or in some cases 
a C-23/C-26 $\gamma$-lactone in the side chain [48]. There is also secosteroid produced by S. sp. For example, the 9,11-secosteroids are structurally characterized by the C-9/11 oxidative cleavage of the C-ring [25]. Steroids isolated from soft corals also exhibit a broad range of biological activities, such as cytotoxic, anti-inflammatory, anti-microbial, etc.

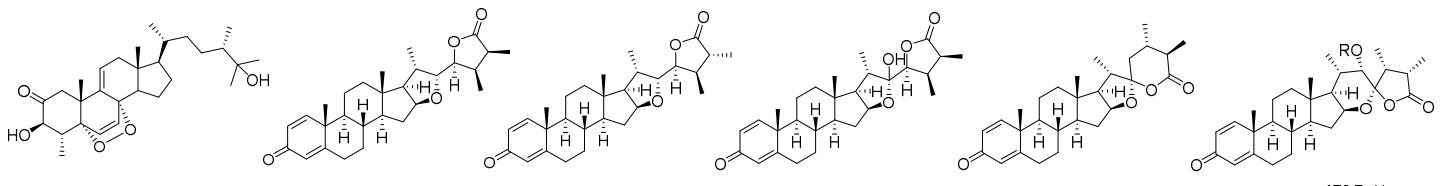

$\begin{array}{llllll}165 & 166 & 167 & 168 & 169 & 170 \mathrm{R}=\mathrm{H} \\ 171 \mathrm{R}=\mathrm{Ac}\end{array}$
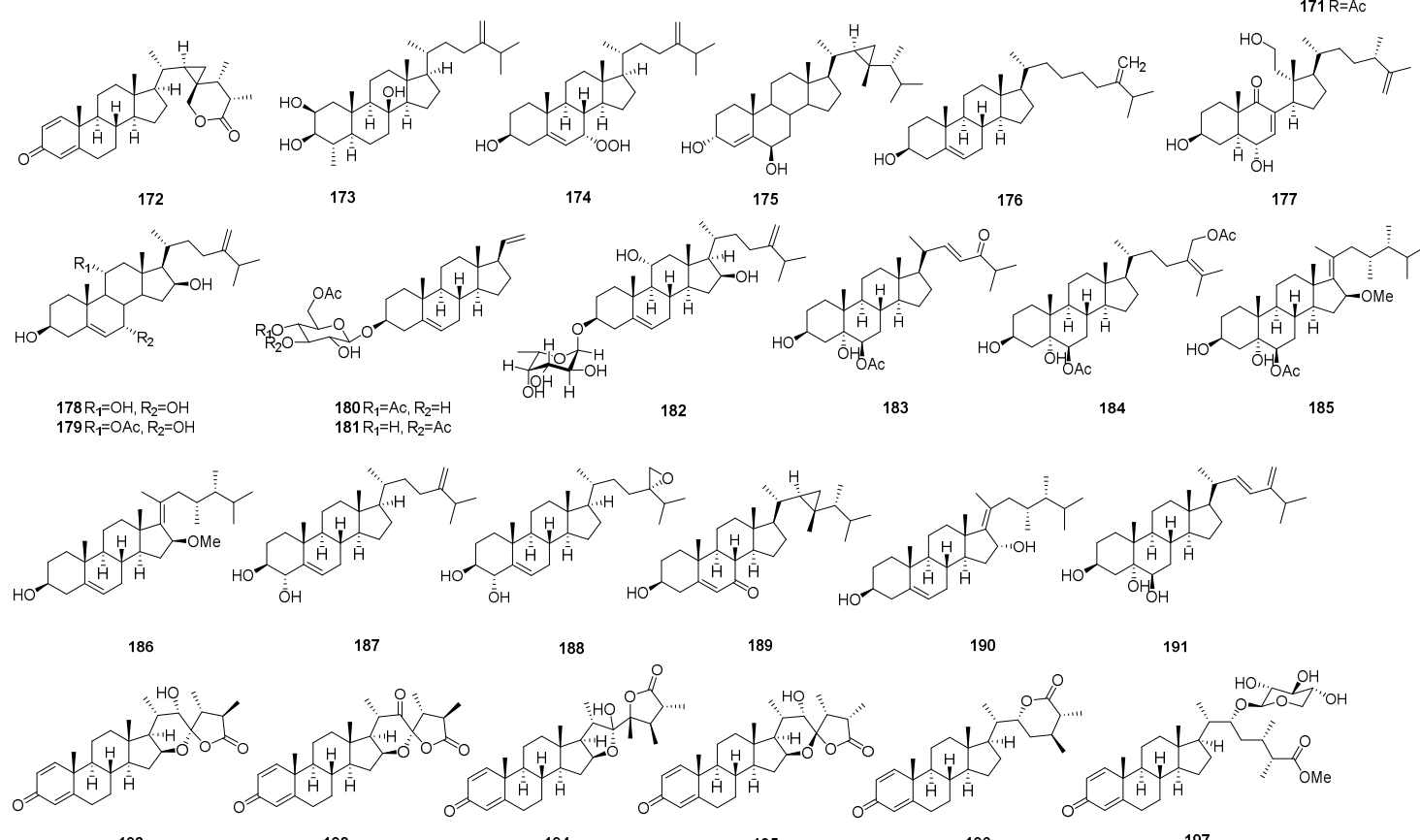

$$
\begin{array}{lllll}
192 & 193 & 194 & 195 & 196
\end{array}
$$
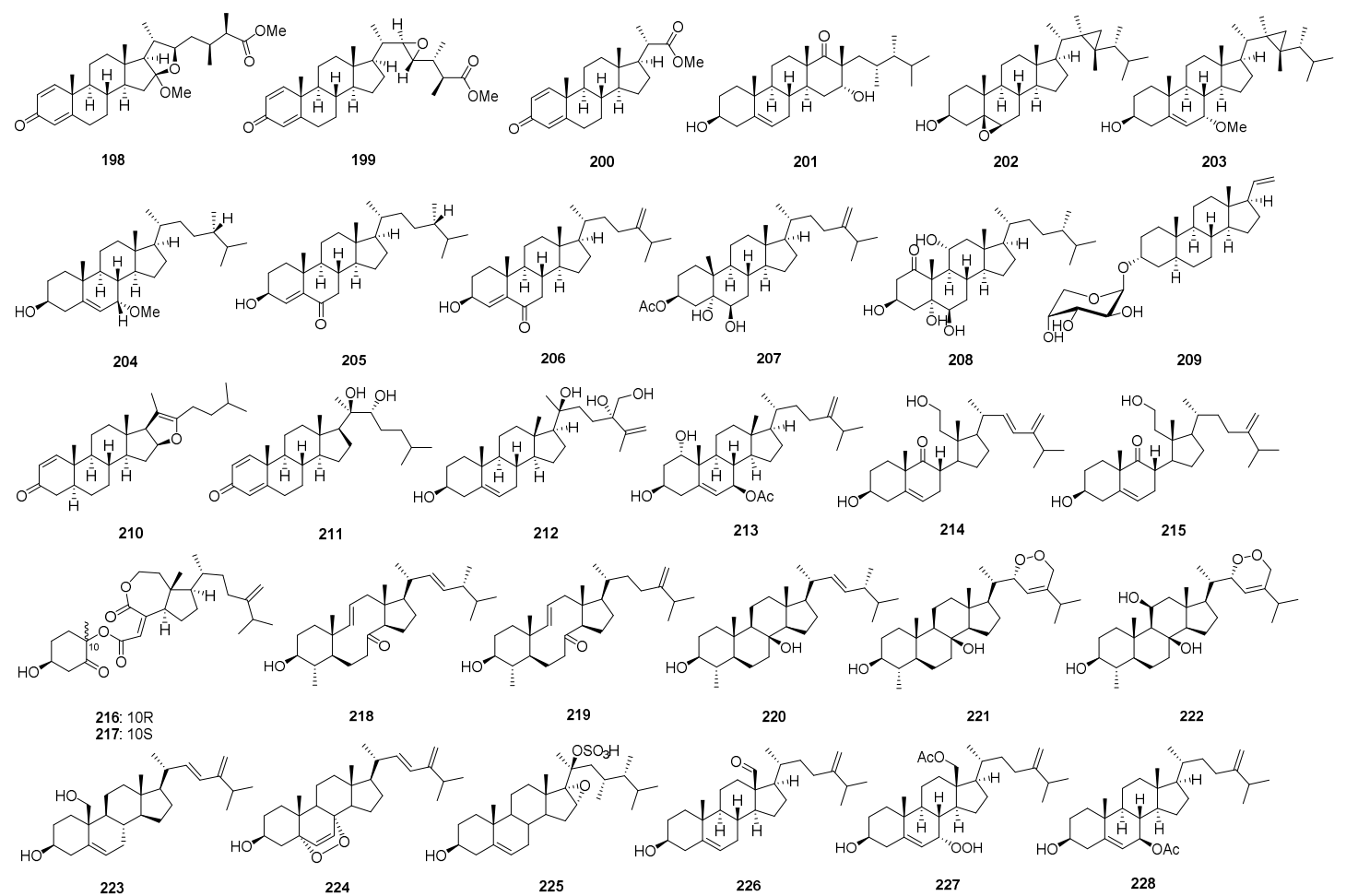

Figure 5. Steroids/steroidal glycosides isolated from genus Sinularia. 
A novel polyhydroxylated sterol, $3 \beta-25$-dihydroxy-4-methyl- $5 \alpha, 8 \alpha$-epidioxy-2 ketoergost-9-ene (165), was isolated from the Red Sea soft coral S. candidula Safaga [86]. It showed antiviral activity against the highly pathogenic H5N1 avian influenza strain.

Seven novel withanolides, sinubrasolides A-G (166-172), have been isolated from the cultured soft coral S. brassica [84]. The cytotoxicities of these compounds against the proliferation of cancer cell lines were evaluated, including murine leukemia (P388) cells, lymphoid T carcinoma (MOLT 4) cells, human erythroleukemia (K562) cells, and human colon carcinoma (HT-29) cells. Compound 167 exhibited cytotoxicity toward P388, MOLT 4, and HT-29 cancer cell lines. Compound $\mathbf{1 7 0}$ was found to show cytotoxicity toward MOLT 4 and HT-29 cell lines. In addition, $\mathbf{1 6 6}$ showed cytotoxicity toward the K562 cell line.

Two new steroids, $(2 \beta, 3 \beta, 4 \alpha, 5 \alpha, 8 \beta)$-4-methylergost-24(28)-ene-2,3,8-triol (173) and $(3 \beta, 7 \alpha)$-24-methyl-7hydroperoxycholest-5,24(28)-diene-3-ol (174) were isolated from the soft coral S. depressa Tixier-Durivault [83]. A wide spectrum of biological activity, including neuroprotective, PTP1B inhibitory, and antibacterial properties were tested but did not show obvious activity [83].

A new steroid, dissesterol (175), was separated from a Vietnamese soft coral S. dissecta [82]. It was confirmed that $\mathbf{1 7 5}$ had no or little effect on the cell viability, and it showed strong suppression of LPS-stimulated IL-12 p40 production [82].

Hurgadacin (176), a 24,25-bishomo-26-methylenecholesterol, was isolated from the Red Sea soft coral S. polydactyla [80]. It was the first steroids with an extended side chain with two methylene units. Compound $\mathbf{1 7 6}$ displayed only marginal cytotoxicity against brine shrimps [80].

A new 9,11-secosteroid, 25(26)-dehydrosarcomilasterol (177), and two new polyhydroxylated steroids, $7 \alpha$-hydroxy-crassarosterol A (178) and 11-acetoxy-7 $\alpha$-hydroxycrassarosterol A (179), were isolated from the South China Sea soft corals Sarcophyton trocheliophorum and S. flexibilis, respectively [74]. Compound 178 exhibited a moderate protein tyrosine phosphatase 1B (PTP1B) inhibitory activity. Compounds 177-179 showed weak in vitro cytotoxicities against the tumor cell lines K562 and HL-60 [74].

Two new pregnane glycosides, hirsutosterosides $A$ and $B$ (180 and 181), and a new steroidal glycoside, lobatasteroside A (182), were isolated from soft coral Cladiella hirsute and S. nanolobata, respectively [67]. Compounds $\mathbf{1 8 0}$ and $\mathbf{1 8 1}$ were found to exhibit the corresponding cytotoxicity toward the four cancer cell lines (K562, P388, HT-29, and A549). Moreover, compound 180 significantly inhibited the fMLP/CB-induced elastase release [67].

Four new polyhydroxylated steroids (183-186) were isolated from the soft coral S. acuta collected from Weizhou Island of Guangxi Province, China [60]. Compound 184 showed potent cytotoxicity against HL-60 cell lines. Compounds 183 and 184 showed weak activities against HeLa cell lines [60].

Two new steroids, $3 \beta, 4 \alpha$-dihydroxyergosta-5,24(28)-diene (187) and 24(S),28-epoxyergost-5-ene-3 $\beta, 4 \alpha$-diol (188), were isolated from the Vietnamese soft coral S. nanolobata [55]. Compound 188 exhibited moderate cytotoxicity against the HL-60 cell line and a weak effect on HepG2 and colon adenocarcinoma (SW480) cell lines [55].

A new polyhydroxysterol (22E)-24-methylenecholestane-22-ene-3 $3,5 \alpha, 6 \beta$-triol (191) was isolated from the South China Sea soft coral S. sp. [50]. It exhibited a cytotoxic effect against both HepG2 and HeLa cell lines [50].

Five new withanolides sinubrasolides H-L (192-196) were separated from soft coral S. brassica [48]. The results of the cytotoxicity test showed that compounds with a hydroxy group at C-22 (192, 194, and 195) exhibited cytotoxic activity against P388, MOLT-4, K-562, and HT-29 cell lines, whereas 193 and 196 showed no activity. Compounds 194-196 also exhibited moderate inhibitory activities against superoxide anion generation. Compounds 192 and 196 also exhibited moderate inhibitory activities against elastase release [48].

Four new steroids with methyl ester groups, sinubrasones A-D (197-200), were obtained from a reef soft coral S. brassica, which was cultured in a tank [12]. Compound 197 possesses a $\beta$-D-xylopyranose. Compounds 198 and 199 were found to show significant 
cytotoxicity against P388D1, MOLT-4, K-562, and HT-29 cell lines. Compounds 197 and 200 exhibited only weak cytotoxic activity against P388D1 and MOLT-4 cell lines. Moreover, 200 showed a significant inhibitory effect $(53.6 \pm 1.8 \%)$ against superoxide anion generation. Compounds 199 and 200 also exhibited inhibitory activities against elastase release [12].

Two new cytotoxic compounds, leptosteroid (201) and 5,6ß-epoxygorgosterol (202), were isolated from the Vietnamese soft coral S. leptoclados [46]. Compound 201 showed significant cytotoxicity against hepatoma cancer and colon adenocarcinoma cell lines [46].

Five new steroids (203-207) were isolated and structurally elucidated from a methanol extract of the Vietnamese soft coral S. conferta [45]. Their cytotoxic effects against three human cancer cell lines, lung carcinoma (A-549), cervical adenocarcinoma (HeLa), and pancreatic epithelioid carcinoma (PANC-1), were evaluated. However, none of them showed obvious activities [45].

A new ergostane-type steroid sinubrassione (208) and a new pregnene-type steroid glycoside sinubrassioside (209) were isolated from methanol extract of the Vietnamese soft coral S. brassica [43]. Cytotoxic activity was observed for compound 208 against PANC-1. No cytotoxicity was observed for compound 209, suggesting that the location of the sugar moiety may be important for the cytotoxicity [43].

Two new steroids, ximaosteroid E (210) and ximaosteroid F (211), were separated from the Chinese soft coral S. sp. [11]. Compound 210 possessed an uncommon dihydrofuran group. Compounds 210 and 211 showed significant cytotoxicity against the HL-60 tumor cell line [11].

Two new highly oxygenated ergostane-type sterols (212 and 213) were isolated from the soft coral S. sp. collected from the Xisha Islands, South China Sea [9]. Compounds 212 and 213 exhibited moderate anti-proliferation effects against five human cancer cell lines, including MDA-MB-436, A549, Hep3B, HT-29, and H157. Compound 212-treated H157 cells displayed apoptosis characteristics. Moreover, Western blot assays suggested that 212 could increase the expression of Bax and down-regulate the expression of Bcl-2 [9].

Two novel 9,11-secosteroids named sinleptosterols A (214) and B (215) were discovered from Taiwan soft coral S. leptoclados [25]. Compounds 214 and 215 were shown to inhibit superoxide anion generation and elastase release by human neutrophils in response to fMLP/CB [25].

A pair of novel highly degraded steroid named Erectsterates A and B (216 and 217) were derived from the South China Sea soft coral S. erecta [2]. These two compounds are rare steroids with a high degradation in ring $B$ and an ester linkage between the $A$ and $\mathrm{C} / \mathrm{D}$ rings. It was proposed that the ring $\mathrm{C}$ of $\mathbf{2 1 6}$ and $\mathbf{2 1 7}$ was formally oxidized by the Baeyer-Villiger reaction to provide an unprecedented seven-membered lactone moiety in ring $C$ of steroid [2]. Compound 217 showed a weak inhibitory effect on the A549, HT29, SNU-398 and Capan-1 cell lines [2].

Six new steroids (218-223) were isolated from the organic extract of the soft coral S. polydactyla collected from the Hurghada reef in the Red Sea [6]. Compounds 218 and 219 displayed the rare 8,9-seco-cholestane steroidal nucleus. Compound 223 displayed increased inhibition of androgen receptors with decreasing concentrations [6].

A new $5 \alpha, 8 \alpha$-epidioxysterol yalongsterol A (224) was isolated from the South China Sea soft coral S. sp. [22]. Compound 224 exhibited moderate activities against the concanavalin A (ConA)-induced proliferation of T lymphocyte cells and LPS-induced proliferation of B lymphocyte cells [22].

A new steroid named 16,17-epoxy-23-methylergostane (225) was derived from $S$. variabilis, which is a soft coral from the Persian Gulf [19]. It showed cytotoxic activity in a dose-dependent reduction manner against MCF-7 and MDA-MB-231. Apoptosis was the underlying mechanism that was enrolled by 225 to induce cell death [19].

Three new oxygenated steroids, sinulasterols A-C (226-228), were isolated from the Chinese soft coral S. depressa [5]. Compounds 226 and 228 featured unusual C-18 oxygenated patterns. In the TNF- $\alpha$ bioassay, 226 and 227 displayed a moderate inhibitory activity [5]. 
The biological activities of new steroids from S. sp. are summarized in Table 5. Many steroids showed interesting cytotoxicity to cancer cell lines, especially withanolides, with a C-22/C-26 $\delta$-lactone or a C-23/C-26 $\gamma$-lactone, which showed significant bioactivities. Some of them displayed anti-inflammatory activity. It is worth mentioning that hydroxy or oxygenic rings on the side chain might be a critical point for the activities, in particular, the cytotoxicities.

Table 5. Biological activities of new steroids from genus Sinularia.

\begin{tabular}{|c|c|c|c|c|}
\hline Drug Class & Compounds & Pharmacology & Activities & Ref \\
\hline \multirow[t]{24}{*}{ Cytotoxicity } & sinubrasolide B (167) & against P388, MOLT 4 and HT-29 & $\mathrm{ED}_{50}: 9.1,4.8,4.8 \mu \mathrm{M}$ & [84] \\
\hline & sinubrasolide E (171) & against $\mathrm{K} 562$ & $\mathrm{ED}_{50}: 9.9,7.5 \mu \mathrm{M}$ & {$[84]$} \\
\hline & sinubrasolide A (166) & against MOLT 4 and HT-30 & $\mathrm{ED}_{50}: 8.7,7.6 \mu \mathrm{M}$ & [84] \\
\hline & $177-179$ & against K562 and HL-60 & $\mathrm{IC}_{50}: 36.28-93.43 \mu \mathrm{M}$ & [74] \\
\hline & 183 & against HeLa & $\mathrm{IC}_{50}: 44.8 \mu \mathrm{M}$ & {$[60]$} \\
\hline & 184 & against HL-60 and HeLa & $\mathrm{IC}_{50}: 7.3,27.1 \mu \mathrm{M}$ & [60] \\
\hline & 188 & against HL-60, HepG2, SW480 & $\mathrm{IC}_{50}: 33.53,64.35,71.02 \mu \mathrm{M}$ & [55] \\
\hline & 191 & against HepG2 and HeLa & $\mathrm{IC}_{50}: 37.30,19.32 \mu \mathrm{M}$ & [50] \\
\hline & sinubrasolide H (192) & against P388, MOLT-4, K-562 and HT-29 & $\mathrm{IC}_{50}: 39.8,28.6,29.7,24.4 \mu \mathrm{M}$ & [48] \\
\hline & sinubrasolide J (194) & against P388, MOLT-4, K-562 and HT-30 & $\mathrm{IC}_{50}: 18.7,17.2,12.6,11.2 \mu \mathrm{M}$ & [48] \\
\hline & sinubrasolide K (195) & against P388, MOLT-4, K-562 and HT-31 & $\mathrm{IC}_{50}: 18.3,13.7,17.4,20.5 \mu \mathrm{M}$ & [48] \\
\hline & sinubrasone A (197) & against P388D1, MOLT-4 & $\mathrm{IC}_{50}: 37.2,37.8 \mu \mathrm{M}$ & [48] \\
\hline & sinubrasone B (198) & against P388D1, MOLT-4, K-562, and HT-29 & $\mathrm{IC}_{50}: 9.7,6.0,5.2,7.6 \mu \mathrm{M}$ & [12] \\
\hline & sinubrasone C (199) & against P388D1, MOLT-4, K-562, and HT-29 & $\mathrm{IC}_{50}: 5.7,5.3,12.1,10.4 \mu \mathrm{M}$ & [12] \\
\hline & sinubrasone D (200) & against P388D1, MOLT-4, K-562, and HT-29 & $\mathrm{IC}_{50}: 24.4,31.2,21.3,36.5 \mu \mathrm{M}$ & {$[12]$} \\
\hline & leptosteroid (201) & against HepG2 and SW480 & $\mathrm{IC}_{50}: 21.13,28.65 \mu \mathrm{M}$ & [46] \\
\hline & sinubrassione (208) & against PANC-1 & $\mathrm{IC}_{50}: 15.24 \mu \mathrm{M}$ & [43] \\
\hline & ximaosteroid E (210) & against HL-60 & $\mathrm{IC}_{50}: 1.79 \mu \mathrm{M}$ & [11] \\
\hline & ximaosteroid F (211) & against HL-60 & $\mathrm{IC}_{50}: 4.03 \mu \mathrm{M}$ & [11] \\
\hline & 212 & against MDA-MB-436, Нер3B, HT-29, and H157 & $\mathrm{IC}_{50}: 17.15,29.28,30.06,10.14 \mu \mathrm{M}$ & [9] \\
\hline & 213 & against MDA-MB-436, A549, Нер3B, HT-29 & $\mathrm{IC}_{50}: 18.21,41.71,19.03,10.38 \mu \mathrm{M}$ & [9] \\
\hline & erectsterate $(\mathbf{2 1 7})$ & against A549, HT29, SNU-398 and Capan-1 & $\mathrm{IC}_{50}: 40.55,32.83,15.57,23.51 \mu \mathrm{M}$ & [2] \\
\hline & 16,17-epoxy-23-methylergostane (225) & against MCF-7 and MDA-MB-231 & $\mathrm{IC}_{50}: 31.44,25.67 \mu \mathrm{M}$ & [19] \\
\hline & 223 & inhibit androgen receptors & inhibition rate: $>100 \%, 10 \mu \mathrm{M}$ & [6] \\
\hline \multirow[t]{11}{*}{ Anti-inflammatory } & dissesterol (175) & IL-12 p40 inhibition & $\mathrm{IC}_{50}: 4.0 \mu \mathrm{M}$ & [82] \\
\hline & sinubrasolide H (192) & inhibit release of elastase & inhibition rate: $32.4 \%, 10 \mu \mathrm{M}$ & [48] \\
\hline & sinubrasolide J (194) & inhibit superoxide anion generation & inhibition rate: $32.1 \%, 10 \mu \mathrm{M}$ & [48] \\
\hline & sinubrasolide K (195) & inhibit superoxide anion generation & inhibition rate: $34.3 \%, 10 \mu \mathrm{M}$ & [48] \\
\hline & sinubrasolide L (196) & $\begin{array}{l}\text { inhibit superoxide anion generation and release } \\
\text { of elastase }\end{array}$ & inhibition rate: $26.3 \%, 25.0 \%, 10 \mu \mathrm{M}$ & [48] \\
\hline & sinubrasone C (199) & inhibit the release of elastase & inhibition rate: $58.8 \%, 10 \mu \mathrm{M}$ & [12] \\
\hline & sinubrasone D (200) & inhibit the release of elastase & inhibition rate: $66.3 \%, 10 \mu \mathrm{M}$ & [12] \\
\hline & sinleptosterol A (214) & $\begin{array}{l}\text { inhibit superoxide anion generation and release } \\
\text { of elastase }\end{array}$ & $\mathrm{IC}_{50}: 7.07,7.57 \mu \mathrm{M}$ & [25] \\
\hline & sinleptosterol B (215) & $\begin{array}{c}\text { inhibit superoxide anion generation and release } \\
\text { of elastase }\end{array}$ & $\mathrm{IC}_{50}: 4.68,4.29 \mu \mathrm{M}$ & [25] \\
\hline & sinulasterol A (226) & TNF- $\alpha$ inhibition & $\mathrm{IC}_{50}: 51.1 \mu \mathrm{M}$ & [5] \\
\hline & sinulasterol B (227) & TNF- $\alpha$ inhibition & $\mathrm{IC}_{50}: 22.7 \mu \mathrm{M}$ & [5] \\
\hline Antidiabetic & $7 \alpha$-hydroxy-crassarosterol A (178) & PTP1B inhibition & $\mathrm{IC}_{50}: 33.05 \mu \mathrm{M}$ & [74] \\
\hline Immunosuppression & yalongsterol A (224) & inhibit $\mathrm{T}$ and $\mathrm{B}$ lymphocyte cells proliferation & $\mathrm{IC}_{50}: 46.0,56.5 \mu \mathrm{M}$ & [22] \\
\hline Antiviral & 165 & against $\mathrm{H} 5 \mathrm{~N} 1$ & inhibition rate: $55.16 \%, 1 \mathrm{ng} / \mathrm{mL}$ & [84] \\
\hline
\end{tabular}

\subsection{Other Types}

In addition to a rich harvest of terpenoids and steroids/steroidal glycosides, $S$. sp. also yields other kinds of metabolites, such as cyclopentenone, ceramides, alkaloid, quinones, and lipids (Figure 6).

Two new cyclopentenone derivatives, $\left(4 S^{*}, 5 S^{*}\right)-4$-hydroxy-5-(hydroxymethyl)-2,3dimethyl-4-pentylcyclopent-2-en-1-one (228) and (S)-4-hydroxy-5-methylene-2,3-dimethyl4-pentylcyclopent-2-en-1-one (229), were isolated from a South China Sea soft coral $S$. verruca [49]. Compounds 228 and 229 were found to be moderately protective against the cytopathic effects of in vitro HIV-1 infection with $\mathrm{EC}_{50}$ values of 34 and $5.8 \mu \mathrm{M}$, respectively, and maximum protection rates of $86 \%$ and $52 \%$, respectively. Their $\mathrm{IC}_{50}$ values for cytotoxicity against the CEM-SS host cells were determined to be 79 and $6.3 \mu \mathrm{M}$. Moreover, compound $\mathbf{2 2 8}$ showed moderate inhibition against lipopolysaccharide-induced NO production in mouse peritoneal macrophages with $\mathrm{IC}_{50}$ values of $28 \mu \mathrm{M}$ [49].

Three new cyclopentenone derivatives, ent-sinulolides C, D, and F (230-232) were isolated from the Paracel Islands soft coral S. cf. molesta [40]. Their cytotoxic (against HeLa, 
HCT-116, BEL-7402, K562, and Jurkat) and inhibitory activities against protein tyrosine phosphatase 1B (PTP1B) were evaluated but showed no obvious activity [40].

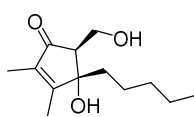

228

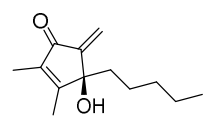

229

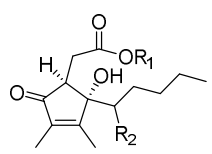

230: $\mathrm{R}_{1}=\mathrm{Me} \mathrm{R} \mathrm{R}_{2}=\mathrm{H}$ 231: $R_{1}=H R_{2}=H$ 232: $\mathrm{R}_{1}=\mathrm{H} \mathrm{R} \mathrm{R}_{2}=\mathrm{OMe}$<smiles>CCCC[C@]1(O)C(C)=C(C)C(=O)C1COC</smiles>

233

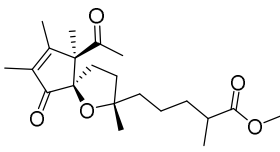

234

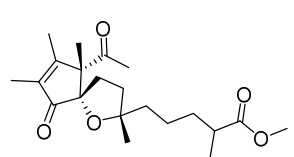

235<smiles>[R20]C(=O)CC1(O)C(=O)C(C)=C(C)C1([R])CCCC</smiles>

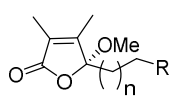<smiles>CCCCC1CCCCC1C(O)CCO</smiles>

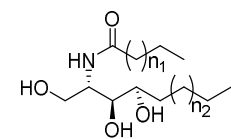

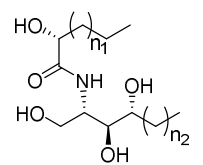
$244 n_{1}=18, n_{2}=19$

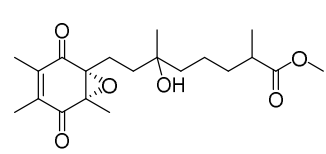

245<smiles>CC(C)=CCC(C)CCC(C)C(C)C(C)CC(C)C(C)Cc1cc(O)c(C)cc1O</smiles>

248

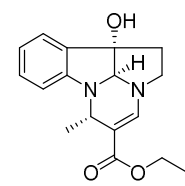

249

Figure 6. Other types of structures isolated from genus Sinularia.

Eight new cyclopentenone and butenolide derivatives, sinulolides A-H (234-241), were isolated from the soft coral S. sp. [68]. At a concentration of $10 \mu \mathrm{g} / \mathrm{mL}$, sinulolide E exhibited moderate effects with an inhibitory rate of $38.12 \%$ [68].

Three new ceramides, $N$-[(2S,3R,E)-1,3-dihydroxyhexacos-4-en-2-yl]icosanamide (242), $\mathrm{N}-[(2 S, 3 S, 4 R)-1,3,4$-trihydroxyhexacosan-2-yl]icosanamide (243), and (R)-2'-hydroxy- $N$ [(2S,3S,4R)-1,3,4-trihydroxypentacosan-2-yl] nonadecanamide (244), were isolated from the Red Sea soft coral S. candidula [86]. The compounds 242-244 showed a reduction of virus titer by $48.81 \%, 10.43 \%$, and $15.76 \%$ at a concentration of $1 \mathrm{ng} / \mathrm{mL}$, respectively.

A new quinone derivative, flexibilisquinone (246), was isolated from the cultured soft coral S. flexibilis [92]. In the in vitro anti-inflammatory effects test, quinone $\mathbf{2 4 6}$ was found to significantly inhibit the accumulation of the pro-inflammatory iNOS and COX-2 proteins of the LPS-stimulated RAW264.7 macrophage cells. Both iNOS and COX-2 were significantly inhibited by compound 246 at $5-20 \mu \mathrm{M}$ and $20 \mu \mathrm{M}$, respectively. Furthermore, compound 246 $(1-20 \mu \mathrm{M})$ did not induce obvious cytotoxicity in macrophage cells.

\section{Conclusions}

Marine invertebrates have been regarded as a treasurable source of bioactive secondary metabolites for drug development. Coral reefs are among the most productive marine ecosystems, which produced a huge diversity of chemical structures with biological properties. The soft corals belonging to the family Sinularia are not an exception. An increasing number of compounds have been reported since the first report of this genus published in 1975 [93]. With the rapid development of analysis, separation, and structure identification technology, more and more new compounds have been isolated and identified each year from soft coral $S$. sp. Until now, more than 150 species of this genus have been found, 78 species among which have been chemically studied, and more than 700 metabolites have been reported. In this review, we have reported 249 compounds along with different structures and potential biological activity based on the data collected from the available literature. The chemical diversity of the structures can be attributed to the chemical groups and the arrangement of the core structure. In particular, sulfur or nitrogen-containing metabolites are a special, relatively rare, and important class of natural products from soft coral (such as compounds 59 and 249), which suggested that the symbiotic microorganisms are the real producers. According to the reported literature, soft 
coral also harbors a microbial community featuring sponges and ascidians [94], including fungus, bacteria, and actinobacteria [95-98], which also corresponds to the antimicrobial activity of coral-derived natural products. The extensive structure-activity relationship studies on the metabolites from Sinularia species are expected, which provide a direction for the discovery of lead compounds. There are also some compounds with novel structures including some new skeletons that tested negative for the limited activity test models and low yield. Therefore, the structure-based drug design methods [18] (e.g., molecular docking, structure-based virtual screening and molecular dynamics) can be utilized in accordance with activity screening.

Author Contributions: X.Y. collected the references and wrote the review. J.L. and X.L. conducted the word processing and graphics. H.O. conceived the review and greatly revised the paper. All authors have read and agreed to the published version of the manuscript.

Funding: This project was financially supported by the National Natural Science Foundation of China (41906092) and Ningbo Municipal Natural Science Foundation (2019A610201).

Institutional Review Board Statement: Not applicable.

Informed Consent Statement: Not applicable.

Data Availability Statement: The data presented in this study are available.

Acknowledgments: We thank the MS center and Fan Wu of Institute of Drug Discovery Technology, Ningbo University.

Conflicts of Interest: The authors declare no conflict of interest.

\section{References}

1. Chen, W.-T.; Li, Y.; Guo, Y.-W. Terpenoids of Sinularia soft corals: Chemistry and bioactivity. Acta Pharm. Sin. B 2012, 2, 227-237. [CrossRef]

2. Liu, J.; Yang, M.; Miao, Z.-H.; Wu, X.; Gu, Y.-C.; Yao, L.-G.; Huan, X.-J.; Luo, H.; Guo, Y.-W. Erectsterates A and B, a pair of novel highly degraded steroid derivatives from the South China Sea soft coral Sinularia erecta. Steroids 2020, 161, 108681. [CrossRef] [PubMed]

3. Huang, C.-Y.; Tseng, Y.-J.; Chokkalingam, U.; Hwang, T.-L.; Hsu, C.-H.; Dai, C.-F.; Sung, P.-J.; Sheu, J.-H. Bioactive isoprenoidderived natural products from a Dongsha Atoll soft coral Sinularia erecta. J. Nat. Prod. 2016, 79, 1339-1346. [CrossRef] [PubMed]

4. Sun, L.-L.; Li, W.-S.; Li, J.; Zhang, H.-Y.; Yao, L.-G.; Luo, H.; Guo, Y.-W.; Li, X.-W. Uncommon Diterpenoids from the South China Sea Soft Coral Sinularia humilis and Their Stereochemistry. J. Org. Chem. 2021, 86, 3367-3376. [CrossRef]

5. Yang, M.; Cui, W.-X.; Li, H.; Tang, W.; Li, S.-W.; Yao, L.-G.; Mudianta, I.W.; Guo, Y.-W. Sinulasterols A-C, three new bioactive oxygenated steroids from the South China Sea soft coral Sinularia depressa. Steroids 2020, 157, 108598. [CrossRef]

6. Tammam, M.A.; Rarova, L.; Kvasnicova, M.; Emam, A.M.; Gonzalez, G.; Mahdy, A.; Strand, M.; Ioannou, E.; Roussis, V. Bioactive Steroids from the Red Sea Soft Coral Sinularia polydactyla. Mar. Drugs 2020, 18, 632. [CrossRef] [PubMed]

7. Liu, J.; Li, H.; Wu, M.-J.; Tang, W.; Wang, J.-R.; Gu, Y.-C.; Wang, H.; Li, X.-W.; Guo, Y.-W. Sinueretone A, a diterpenoid with unprecedented tricyclo[12.1.0.0(5,9)]pentadecane carbon scaffold from the South China Sea soft coral Sinularia erecta. J. Org. Chem. 2020. Ahead of print. [CrossRef]

8. Cai, Y.-S.; Cui, W.-X.; Tang, W.; Guo, Y.-W. Uncommon terpenoids with anti-inflammatory activity from the Hainan soft coral Sinularia tumulosa. Bioorg. Chem. 2020, 104, 104167. [CrossRef]

9. Jiang, C.-S.; Ru, T.; Huan, X.-J.; Miao, Z.-H.; Guo, Y.-W. New cytotoxic ergostane-type sterols from the Chinese soft coral Sinularia sp. Steroids 2019, 149, 108425. [CrossRef]

10. Qin, G.-F.; Tang, X.-L.; Sun, Y.-T.; Luo, X.-C.; Zhang, J.; Ofwegen, L.V.; Sung, P.-J.; Li, P.-L.; Li, G.-Q. Terpenoids from the Soft Coral Sinularia sp. Collected in Yongxing Island. Mar. Drugs 2018, 16, 127. [CrossRef]

11. Li, S.-W.; Chen, W.-T.; Yao, L.-G.; Guo, Y.-W. Two new cytotoxic steroids from the Chinese soft coral Sinularia sp. Steroids 2018, 136, 17-21. [CrossRef]

12. Huang, C.-Y.; Su, J.-H.; Liaw, C.-C.; Sung, P.-J.; Chiang, P.-L.; Hwang, T.-L.; Dai, C.-F.; Sheu, J.-H. Bioactive Steroids with Methyl Ester Group in the Side Chain from a Reef Soft Coral Sinularia brassica Cultured in a Tank. Mar. Drugs 2017, 15, 280. [CrossRef]

13. Thao, N.P.; Nam, N.H.; Cuong, N.X.; Quang, T.H.; Tung, P.T.; Dat, L.D.; Chae, D.; Kim, S.; Koh, Y.-S.; Van Kiem, P.; et al. Anti-inflammatory norditerpenoids from the soft coral Sinularia maxima. Bioorg. Med. Chem. Lett. 2013, 23, 228-231. [CrossRef] [PubMed]

14. Lai, D.; Geng, Z.; Deng, Z.; Van Ofwegen, L.; Proksch, P.; Lin, W. Cembranoids from the Soft Coral Sinularia rigida with Antifouling Activities. J. Agric. Food Chem. 2013, 61, 4585-4592. [CrossRef] 
15. Liang, L.-F.; Li, Y.-F.; Liu, H.-L.; Guo, Y.-W. Research advance on the chemistry and bioactivity of secondary metabolites from the soft corals of the genus Sinularia. Guoji Yaoxue Yanjiu Zazhi 2013, 40, 643-669.

16. Sheu, J.-H.; Peng, B.-R.; Fang, L.-S.; Hwang, T.-L.; Su, J.-H.; Wu, Y.-C.; Sung, P.-J. Hydroperoxyditerpenoids from Octocorals. Isr. J. Chem. 2019, 59, 403-413. [CrossRef]

17. Lakshmi, V.; Kumar, R. Metabolites from Sinularia species. Nat. Prod. Res. 2009, 23, 801-850. [CrossRef] [PubMed]

18. Rodrigues, I.G.; Miguel, M.G.; Mnif, W. A brief review on new naturally occurring cembranoid diterpene derivatives from the soft corals of the Genera Sarcophyton, Sinularia, and Lobophytum since 2016. Molecules 2019, 24, 781. [CrossRef] [PubMed]

19. Mohammadi, P.P.; Yegdaneh, A.; Aghaei, M.; Ali, Z.; Khan, I.A.; Ghanadian, M. Novel 16,17-epoxy-23-methylergostane derivative from Sinularia variabilis, a soft coral from the Persian Gulf, with apoptotic activities against breast cancer cell lines. Nat. Prod. Res. 2021, 1-10. [CrossRef] [PubMed]

20. Lu, Y.-H.; Lin, J.-J.; Wu, Y.-J.; Su, J.-H.; El-Shazly, M. Quinone Derivatives from the Soft Coral Sinularia scabra. Chem. Nat. Compd. 2021, 57, 6-8. [CrossRef]

21. Ye, F.; Chen, Z.-H.; Gu, Y.-C.; Guo, Y.-W.; Li, X.-W. New lobane-type diterpenoids from the Xisha soft coral Sinularia polydactyla. Chin. J. Nat. Med. 2020, 18, 839-843.

22. Yang, M.; Liang, L.-F.; Li, H.; Tang, W.; Guo, Y.-W. A new $5 \alpha, 8 \alpha$-epidioxysterol with immunosuppressive activity from the South China Sea soft coral Sinularia sp. Nat. Prod. Res. 2020, 34, 1814-1819. [CrossRef] [PubMed]

23. Li, J.; Huan, X.-J.; Wu, M.-J.; Chen, Z.-H.; Chen, B.; Miao, Z.-H.; Guo, Y.-W.; Li, X.-W. Chemical constituents from the South China sea soft coral Sinularia humilis. Nat. Prod. Res. 2020, 1-7. [CrossRef]

24. Cui, W.-X.; Yang, M.; Li, G.; Li, H.; Tang, W.; Li, S.-W.; Yao, L.-G.; Wang, C.-H.; Liang, L.-F.; Guo, Y.-W. Polycyclic furanobutenolidederived norditerpenoids from the South China Sea soft corals Sinularia scabra and Sinularia polydactyla with immunosuppressive activity. Bioorg. Chem. 2020, 94, 103350. [CrossRef] [PubMed]

25. Chang, Y.-C.; Lai, K.-H.; Kumar, S.; Chen, P.-J.; Wu, Y.-H.; Lai, C.-L.; Hsieh, H.-L.; Sung, P.-J.; Hwang, T.-L. NMR H ${ }^{1}$-based isolation of anti-inflammatory 9,11-secosteroids from the octocoral Sinularia leptoclados. Mar. Drugs 2020, 18, 271. [CrossRef] [PubMed]

26. Yang, M.; Li, G.; Li, H.; Zhang, Q.; Wu, Q.-H.; Chen, K.-X.; Guo, Y.-W.; Li, X.-W.; Tang, W. Highly diverse cembranoids from the South China Sea soft coral Sinularia scabra as a new class of potential immunosuppressive agents. Bioorg. Med. Chem. 2019, 27, 3469-3476. [CrossRef] [PubMed]

27. Wu, Q.; Li, X.-W.; Li, H.; Yao, L.-G.; Tang, W.; Miao, Z.-H.; Wang, H.; Guo, Y.-W. Bioactive polyoxygenated cembranoids from a novel Hainan chemotype of the soft coral Sinularia flexibilis. Bioorg. Med. Chem. Lett. 2019, 29, 185-188. [CrossRef] [PubMed]

28. Wang, Z.; Li, P.-L.; Luo, X.-C.; Wang, Q.; Ofwegen, L.V.; Tang, X.L.; Li, G.-Q. Terpenoids from the South China Sea soft coral Sinularia multiflora. Nat. Prod. Res. 2019, 1-8. [CrossRef]

29. Phan, C.-S.; Yee, C.-S.; Vairappan, C.S.; Ishii, T.; Kamada, T. Sinulaflexiolide P, A Cembrane-Type Diterpenoid from Bornean Soft Coral Sinularia flexibilis. Chem. Nat. Compd. 2019, 55, 285-288. [CrossRef]

30. Lu, S.-Q.; Li, X.-W.; Li, S.-W.; Cui, Z.; Guo, Y.-W.; Han, G.-Y. Sinuhirtins A and B, two uncommon norhumulene-type terpenoids from the South China Sea soft coral Sinularia hirta. Tetrahedron Lett. 2019, 60, 151308. [CrossRef]

31. Lai, W.; Zou, G.; Liao, X.-J.; Zhang, H.; Zhao, B.-X.; Xu, S.-H.; Qin, S.-Y.; Chen, G.-D. Sinulaspirolactam A, a novel aza-spirocyclic valerenane sesquiterpenoid from soft coral Sinularia sp. J. Asian Nat. Prod. Res. 2019, 21, 494-500. [CrossRef] [PubMed]

32. Jiang, C.-S.; Ru, T.; Yao, L.-G.; Miao, Z.-H.; Guo, Y.-W. Four new cembranoids from the Chinese soft coral Sinularia sp. and their anti-A $\beta$ aggregation activities. Fitoterapia 2019, 136, 104176. [CrossRef] [PubMed]

33. Huong, N.T.; Ngoc, N.T.; Hanh, T.T.H.; Quang, T.H.; Cuong, N.X.; Nam, N.H.; Van Minh, C. Chemical constituents from the soft coral Sinularia digitata. Vietnam. J. Chem. 2019, 57, 636-640. [CrossRef]

34. Ye, F.; Zhu, Z.-D.; Gu, Y.C.; Li, J.; Zhu, W.-L.; Guo, Y.-W. Further New Diterpenoids as PTP1B Inhibitors from the Xisha Soft Coral Sinularia polydactyla. Mar. Drugs 2018, 16, 103. [CrossRef]

35. Wu, C.-H.; Chao, C.-H.; Huang, T.-Z.; Huang, C.-Y.; Hwang, T.-L.; Dai, C.-F.; Sheu, J.-H. Cembranoid-Related Metabolites and Biological Activities from the Soft Coral Sinularia flexibilis. Mar. Drugs 2018, 16, 278. [CrossRef]

36. Kamada, T.; Phan, C.-S.; Zanil, I.I.; Vairappan, C.S.; Kang, M.-C.; Jeon, Y.-J. Bioactive cembranoids from the soft coral Genus Sinularia sp. in Borneo. Mar. Drugs 2018, 16, 99. [CrossRef]

37. Kamada, T.; Phan, C.-S.; Hamada, T.; Hatai, K.; Vairappan, C.S. Cytotoxic and Antifungal Terpenoids from Bornean Soft Coral, Sinularia flexibilis. Nat. Prod. Commun. 2018, 13, 17-19. [CrossRef]

38. Huong, N.T.; Ngoc, N.T.; Thanh, N.V.; Dang, N.H.; Cuong, N.X.; Nam, N.H.; Kiem, P.V.; Minh, C.V.; Cuong, N.X.; Thung, D.C.; et al. Eudesmane and aromadendrane sesquiterpenoids from the Vietnamese soft coral Sinularia erecta. Nat. Prod. Res. 2018, 32, 1798-1802. [CrossRef]

39. Hsu, F.-Y.; Duh, C.-Y.; Wang, S.-K. Xeniaphyllane-Derived Terpenoids from Soft Coral Sinularia nanolobata. Mar. Drugs 2018, 16, 40. [CrossRef]

40. Chu, M.-J.; Tang, X.-L.; Han, X.; Li, T.; Luo, X.-C.; Jiang, M.-M.; Van Ofwegen, L.; Luo, L.-Z.; Zhang, G.; Li, P.-L.; et al. Metabolites from the Paracel Islands Soft Coral Sinularia cf. molesta. Mar. Drugs 2018, 16, 517. [CrossRef]

41. Ye, F.; Zhu, Z.-D.; Chen, J.-S.; Li, J.; Gu, Y.-C.; Zhu, W.-L.; Li, X.-W.; Guo, Y.-W. Xishacorenes A-C, Diterpenes with Bicyclo[3.3.1]nonane Nucleus from the Xisha Soft Coral Sinularia polydactyla. Org. Lett. 2017, 19, 4183-4186. [CrossRef] 
42. Wang, J.; Su, P.; Gu, Q.; Li, W.D.; Guo, J.L.; Qiao, W.; Feng, D.Q.; Tang, S.A. Antifouling activity against bryozoan and barnacle by cembrane diterpenes from the soft coral Sinularia flexibilis. Int. Biodeterior. Biodegrad. 2017, 120, 97-103. [CrossRef]

43. Ngoc, N.T.; Hanh, T.T.H.; Nguyen, V.T.; Thao, D.T.; Cuong, N.X.; Nguyen, H.N.; Thung, D.C.; Kiem, P.V.; Minh, C.V. Cytotoxic steroid derivatives from the Vietnamese soft coral Sinularia brassica. J. Asian Nat. Prod. Res. 2017, 19, 1183-1190. [CrossRef] [PubMed]

44. Ngoc, N.T.; Huong, P.T.M.; Thanh, N.V.; Cuong, N.X.; Nam, N.H.; Thung, D.C.; Kiem, P.V.; Minh, C.V. Sesquiterpene constituents from the soft coral Sinularia nanolobata. Nat. Prod. Res. 2017, 31, 1799-1804. [CrossRef]

45. Ngoc, N.T.; Huong, P.T.M.; Thanh, N.V.; Chi, N.T.P.; Dang, N.H.; Cuong, N.X.; Nam, N.H.; Thung, D.C.; Kiem, P.V.; Minh, C.V. Cytotoxic Steroids from the Vietnamese Soft Coral Sinularia conferta. Chem. Pharm. Bull. 2017, 65, 300-305. [CrossRef]

46. Ngoc, N.T.; Hanh, T.T.H.; Thanh, N.V.; Thao, D.T.; Cuong, N.X.; Nam, N.H.; Thung, D.C.; Kiem, P.V.; Minh, C.V. Cytotoxic steroids from the Vietnamese soft coral Sinularia leptoclados. Chem. Pharm. Bull. 2017, 65, 593-597. [CrossRef]

47. Mohammed, R.; Radwan, M.M.; Ma, G.; Mohamed, T.A.; Seliem, M.A.; Thabet, M.; ElSohly, M.A. Bioactive sterols and sesquiterpenes from the Red Sea soft coral Sinularia terspilli. Med. Chem. Res. 2017, 26, 1647-1652. [CrossRef]

48. Huang, C.-Y.; Ahmed, A.F.; Su, J.-H.; Sung, P.-J.; Hwang, T.-L.; Chiang, P.-L.; Dai, C.-F.; Liaw, C.-C.; Sheu, J.-H. Bioactive new withanolides from the cultured soft coral Sinularia brassica. Bioorg. Med. Chem. Lett. 2017, 27, 3267-3271. [CrossRef]

49. Yuan, W.; Cheng, S.; Fu, W.; Zhao, M.; Li, X.; Cai, Y.; Dong, J.; Huang, K.; Gustafson, K.R.; Yan, P. Structurally diverse metabolites from the soft coral Sinularia verruca collected in the South China Sea. J. Nat. Prod. 2016, 79, 1124-1131. [CrossRef] [PubMed]

50. Sun, H.; Liu, F.; Feng, M.-R.; Peng, Q.; Liao, X.-J.; Liu, T.-T.; Xu, S.-H.; Zhang, J. Isolation of a new cytotoxic polyhydroxysterol from the South China Sea soft coral Sinularia sp. Nat. Prod. Res. 2016, 30, 2819-2824. [CrossRef] [PubMed]

51. Roy, P.K.; Ashimine, R.; Ueda, K.; Miyazato, H.; Taira, J. Endoperoxy and hydroperoxy cadinane-type sesquiterpenoids from an Okinawan soft coral, Sinularia sp. Arch. Pharmacal Res. 2016, 39, 778-784. [CrossRef]

52. Rahelivao, M.P.; Gruner, M.; Lübken, T.; Islamov, D.; Kataeva, O.; Andriamanantoanina, H.; Bauer, I.; Knölker, H.-J. Chemical constituents of the soft corals Sinularia vanderlandi and Sinularia gravis from the coast of Madagascar. Org. Biomol. Chem. 2016, 14, 989-1001. [CrossRef]

53. Phan, C.-S.; Ng, S.Y.; Kamada, T.; Vairappan, C.S. Two New Lobane Diterpenes from a Bornean Soft Coral Sinularia sp. Nat. Prod. Commun. 2016, 11, 899-900. [CrossRef]

54. Nguyen, V.T.; Ngoc, N.T.; Anh, H.L.T.; Thung, D.C.; Thao, D.T.; Nguyen, X.C.; Nguyen, H.N.; Kiem, P.V.; Minh, C.V. Steroid constituents from the soft coral Sinularia microspiculata. J. Asian Nat. Prod. Res. 2016, 18, 938-944.

55. Ngoc, N.T.; Huong, P.T.M.; Thanh, N.V.; Cuong, N.X.; Nam, N.H.; Thung, D.C.; Kiem, P.V.; Minh, C.V. Steroid Constituents from the Soft Coral Sinularia nanolobata. Chem. Pharm. Bull. 2016, 64, 1417-1419. [CrossRef]

56. Lin, Y.-S.; Su, J.-H.; Lo, C.-L.; Huang, C.-Y.; Sheu, J.-H. Isobicyclogermacrene-type Sesquiterpenoids from the Soft Coral Sinularia lochmodes. Nat. Prod. Commun. 2016, 11, 577-578. [CrossRef] [PubMed]

57. Hegazy, M.-E.F.; Mohamed, T.A.; ElShamy, A.I.; Al-Hammady, M.A.; Ohta, S.; Paré, P.W. Casbane Diterpenes from Red Sea Coral Sinularia polydactyla. Molecules 2016, 21, 308. [CrossRef] [PubMed]

58. Chitturi, B.R.; Tatipamula, V.B.; Dokuburra, C.B.; Mangamuri, U.K.; Tuniki, V.R.; Kalivendi, S.V.; Bunce, R.A.; Yenamandra, V. Pambanolides A-C from the South Indian soft coral Sinularia inelegans. Tetrahedron 2016, 72, 1933-1940. [CrossRef]

59. Chao, C.-H.; Wu, C.-Y.; Huang, C.-Y.; Wang, H.-C.; Dai, C.-F.; Wu, Y.-C.; Sheu, J.-H. Cubitanoids and Cembranoids from the Soft Coral Sinularia nanolobata. Mar. Drugs 2016, 14, 150. [CrossRef] [PubMed]

60. Zhang, N.-X.; Tang, X.-L.; van Ofwegen, L.; Xue, L.; Song, W.-J.; Li, P.-L.; Li, G.-Q. Cyclopentenone derivatives and polyhydroxylated steroids from the soft coral Sinularia acuta. Chem. Biodivers. 2015, 12, 273-283. [CrossRef]

61. Yin, C.-T.; Wen, Z.-H.; Lan, Y.-H.; Chang, Y.-C.; Wu, Y.-C.; Sung, P.-J. New Anti-inflammatory Norcembranoids from the Soft Coral Sinularia numerosa. Chem. Pharm. Bull. 2015, 63, 752-756. [CrossRef]

62. Yang, B.; Huang, J.; Lin, X.; Liao, S.; Zhou, X.; Liu, J.; Wang, J.; Wang, L.; Liu, Y. New Casbane Diterpenoids from the Hainan Soft Coral Sinularia Species. Helv. Chim. Acta 2015, 98, 834-841. [CrossRef]

63. Tsai, T.-C.; Chen, H.-Y.; Sheu, J.-H.; Chiang, M.Y.; Wen, Z.-H.; Dai, C.-F.; Su, J.-H. Structural Elucidation and Structure-Antiinflammatory Activity Relationships of Cembranoids from Cultured Soft Corals Sinularia sandensis and Sinularia flexibilis. J. Agric. Food Chem. 2015, 63, 7211-7218. [CrossRef]

64. Lin, W.-J.; Wu, T.-Y.; Su, T.-R.; Wen, Z.-H.; Chen, J.-J.; Fang, L.-S.; Wu, Y.-C.; Sung, P.-J. Terpenoids from the octocoral Sinularia gaweli. Int. J. Mol. Sci. 2015, 16, 19508-19517. [CrossRef] [PubMed]

65. Chen, W.-T.; Li, J.; Wang, J.-R.; Li, X.-W.; Guo, Y.-W. Structural diversity of terpenoids in the soft coral Sinularia flexibilis, evidenced by a collection from the South China Sea. RSC Adv. 2015, 5, 23973-23980. [CrossRef]

66. Chen, W.-F.; Yin, C.-T.; Cheng, C.-H.; Lu, M.-C.; Fang, L.-S.; Wang, W.-H.; Wen, Z.-H.; Chen, J.-J.; Wu, Y.-C.; Sung, P.-J. Norcembranoidal Diterpenes from the Cultured-Type Octocoral Sinularia numerosa. Int. J. Mol. Sci. 2015, 16, 3298-3306. [CrossRef]

67. Chao, C.-H.; Huang, T.-Z.; Wu, C.-Y.; Chen, B.-W.; Huang, C.-Y.; Hwang, T.-L.; Dai, C.-F.; Sheu, J.-H. Steroidal and $\alpha-$ tocopherylhydroquinone glycosides from two soft corals Cladiella hirsuta and Sinularia nanolobata. RSC Adv. 2015, 5, 74256-74262. [CrossRef]

68. Yang, B.; Lin, X.; Liu, J.; Liao, S.; Wang, J.; Zhou, X.; Liu, Y.; Wei, X.; Huang, J.; Wang, L. Sinulolides A-H, new cyclopentenone and butenolide derivatives from soft coral Sinularia sp. Mar. Drugs 2014, 12, 5316-5327. [CrossRef] 
69. Wang, L.-H.; Chen, K.-H.; Dai, C.-F.; Hwang, T.-L.; Wang, W.-H.; Wen, Z.-H.; Wu, Y.-C.; Sung, P.-J. New Cembranoids from the Soft Coral Sinularia arborea. Nat. Prod. Commun. 2014, 9, 361-362. [CrossRef]

70. Rajaram, S.; Ramesh, D.; Ramulu, U.; Anjum, M.; Kumar, P.; Murthy, U.S.N.; Hussain, M.A.; Sastry, G.N.; Venkateswarlu, Y. Chemical examination of the soft coral Sinularia kavarattiensis and evaluation of anti-microbial activity. Indian J. Chem. Sect. B Org. Chem. Incl. Med. Chem. 2014, 53B, 1086-1090.

71. Lillsunde, K.-E.; Festa, C.; Adel, H.; De Marino, S.; Lombardi, V.; Tilvi, S.; Nawrot, D.A.; Zampella, A.; D'Souza, L.; D'Auria, M.V.; et al. Bioactive Cembrane Derivatives from the Indian Ocean Soft Coral, Sinularia kavarattiensis. Mar. Drugs 2014, 12, $4045-4068$. [CrossRef]

72. Lei, L.-F.; Chen, M.-F.; Wang, T.; He, X.-X.; Liu, B.-X.; Deng, Y.; Chen, X.-J.; Li, Y.-T.; Guan, S.-Y.; Yao, J.-H.; et al. Novel cytotoxic nine-membered macrocyclic polysulfur cembranoid lactones from the soft coral Sinularia sp. Tetrahedron 2014, 70, 6851-6858. [CrossRef]

73. Jiang, C.-S.; Li, Y.; Han, G.-Y.; Guo, Y.-W. Further casbane-type diterpenes from the soft coral Sinularia depressa. Zhongguo Tianran Yaowu 2014, 12, 853-856. [CrossRef]

74. Chen, W.-T.; Liu, H.-L.; Yao, L.-G.; Guo, Y.-W. 9,11-Secosteroids and polyhydroxylated steroids from two South China Sea soft corals Sarcophyton trocheliophorum and Sinularia flexibilis. Steroids 2014, 92, 56-61. [CrossRef] [PubMed]

75. Chen, K.-H.; Dai, C.-F.; Hwang, T.-L.; Chen, C.-Y.; Li, J.-J.; Chen, J.-J.; Wu, Y.-C.; Sheu, J.-H.; Wang, W.-H.; Sung, P.-J. Discovery of novel diterpenoids from Sinularia arborea. Mar. Drugs 2014, 12, 385-393. [CrossRef]

76. Chen, D.; Cheng, W.; Liu, D.; Van Ofwegen, L.; Proksch, P.; Lin, W. Capillosananes S-Z, new sesquiterpenoids from the soft coral Sinularia capillosa. Tetrahedron Lett. 2014, 55, 3077-3082. [CrossRef]

77. Yin, J.; Zhao, M.; Ma, M.; Xu, Y.; Xiang, Z.; Cai, Y.; Dong, J.; Lei, X.; Huang, K.; Yan, P. New Casbane Diterpenoids from a South China Sea Soft Coral, Sinularia sp. Mar. Drugs 2013, 11, 455-465. [CrossRef] [PubMed]

78. Yang, B.; Liao, S.; Lin, X.; Wang, J.; Liu, J.; Zhou, X.; Yang, X.; Liu, Y. New Sinularianin sesquiterpenes from soft coral Sinularia sp. Mar. Drugs 2013, 11, 4741-4750. [CrossRef]

79. Tsai, T.-C.; Wu, Y.-J.; Su, J.-H.; Lin, W.-T.; Lin, Y.-S. A new spatane diterpenoid from the cultured soft coral Sinularia leptoclados. Mar. Drugs 2013, 11, 114-123. [CrossRef] [PubMed]

80. Shaaban, M.; Shaaban, K.A.; Ghani, M.A. Hurgadacin: A new steroid from Sinularia polydactyla. Steroids 2013, 78, 866-873. [CrossRef] [PubMed]

81. Rajaram, S.; Ramulu, U.; Ramesh, D.; Srikanth, D.; Bhattacharya, P.; Prabhakar, P.; Kalivendi, S.V.; Babu, K.S.; Venkateswarlu, Y.; Navath, S. Anti-cancer evaluation of carboxamides of furano-sesquiterpene carboxylic acids from the soft coral Sinularia kavarattiensis. Bioorg. Med. Chem. Lett. 2013, 23, 6234-6238. [CrossRef]

82. Nguyen, P.T.; Nguyen, H.N.; Nguyen, X.C.; Tai, B.H.; Quang, T.H.; Nguyen, T.T.N.; Luyen, B.T.T.; Yang, S.Y.; Choi, C.H.; Kim, S.; et al. Steroidal constituents from the soft coral Sinularia dissecta and their inhibitory effects on lipopolysaccharide-stimulated production of pro-inflammatory cytokines in bone marrow-derived dendritic cells. Bull. Korean Chem. Soc. 2013, 34, 949-952. [CrossRef]

83. Liang, L.-F.; Wang, X.-J.; Zhang, H.-Y.; Liu, H.-L.; Li, J.; Lan, L.-F.; Zhang, W.; Guo, Y.-W. Bioactive polyhydroxylated steroids from the Hainan soft coral Sinularia depressa Tixier-Durivault. Bioorg. Med. Chem. Lett. 2013, 23, 1334-1337. [CrossRef] [PubMed]

84. Huang, C.-Y.; Liaw, C.-C.; Chen, B.-W.; Chen, P.-C.; Su, J.-H.; Sung, P.-J.; Dai, C.-F.; Chiang, M.Y.; Sheu, J.-H. Withanolide-Based Steroids from the Cultured Soft Coral Sinularia brassica. J. Nat. Prod. 2013, 76, 1902-1908. [CrossRef]

85. Hu, L.-C.; Yen, W.-H.; Su, J.-H.; Chiang, M.Y.-N.; Wen, Z.-H.; Chen, W.-F.; Lu, T.-J.; Chang, Y.-W.; Chen, Y.-H.; Wang, W.-H.; et al. Cembrane Derivatives from the Soft Corals, Sinularia gaweli and Sinularia flexibilis. Mar. Drugs 2013, 11, 2154-2167. [CrossRef]

86. Ahmed, S.; Ibrahim, A.; Arafa, A.S. Anti-H5N1 virus metabolites from the Red Sea soft coral, Sinularia candidula. Tetrahedron Lett. 2013, 54, 2377-2381. [CrossRef]

87. Aboutabl, E.-S.A.; Azzam, S.M.; Michel, C.G.; Selim, N.M.; Hegazy, M.F.; Ali, A.-H.A.M.; Hussein, A.A. Bioactive terpenoids from the Red Sea soft coral Sinularia polydactyla. Nat. Prod. Res. 2013, 27, 2224-2226. [CrossRef]

88. Wu, M.-J.; Wang, H.; Jiang, C.-S.; Guo, Y.-W. New cembrane-type diterpenoids from the South China Sea soft coral Sinularia crassa and their $\alpha$-glucosidase inhibitory activity. Bioorg. Chem. 2020, 104, 104281. [CrossRef]

89. Khushi, S.; Salim, A.A.; Elbanna, A.H.; Nahar, L.; Bernhardt, P.V.; Capon, R.J. Dysidealactams and dysidealactones: Sesquiterpene glycinyl-lactams, imides, and lactones from a Dysidea sp. marine sponge collected in southern Australia. J. Nat. Prod. 2020, 83, 1577-1584. [CrossRef]

90. Imperatore, C.; Gimmelli, R.; Persico, M.; Casertano, M.; Guidi, A.; Saccoccia, F.; Ruberti, G.; Luciano, P.; Aiello, A.; Parapini, S.; et al. Investigating the Antiparasitic Potential of the Marine Sesquiterpene Avarone, Its Reduced Form Avarol, and the Novel Semisynthetic Thiazinoquinone Analogue Thiazoavarone. Mar. Drugs 2020, 18, 112. [CrossRef]

91. Rosa, S.D.; Iodice, C.; Khalaghdoust, M.; Oryan, S.; Rustaiyan, A. Spatane diterpenoids from the brown alga Stoechospermum marginatum (Dictyotaceae). Phytochemistry 1999, 51, 1009-1012. [CrossRef]

92. Lin, Y.-F.; Kuo, C.-Y.; Wen, Z.-H.; Lin, Y.-Y.; Wang, W.-H.; Su, J.-H.; Sheu, J.-H.; Sung, P.-J. Flexibilisquinone, a new antiinflammatory quinone from the cultured soft coral Sinularia flexibilis. Molecules 2013, 18, 8160-8167. [CrossRef]

93. Tursch, B.; Braekman, J.C.; Daloze, D.; Herin, M.; Karlsson, R.; Losman, D. Chemical studies of marine invertebrates. XI. Sinulariolide, a new cembranolide diterpene from the soft coral Sinularia flexibilis. Tetrahedron 1975, 31, 129-133. [CrossRef] 
94. Casertano, M.; Menna, M.; Imperatore, C. The Ascidian-Derived Metabolites with Antimicrobial Properties. Antibiotics 2020, 9 , 510. [CrossRef] [PubMed]

95. Li, J.; Tao, H.; Lei, X.-X.; Zhang, H.; Zhou, X.; Liu, Y.; Li, Y.; Yang, B. Arthriniumsteroids A-D, four new steroids from the soft coral-derived fungus Simplicillium lanosoniveum SCSIO41212. Steroids 2021, 171, 108831. [CrossRef] [PubMed]

96. Xu, W.-F.; Chao, R.; Hai, Y.; Guo, Y.-Y.; Wei, M.-Y.; Wang, C.-Y.; Shao, C.-L. 17-Hydroxybrevianamide N and Its N1-Methyl Derivative, Quinazolinones from a Soft-Coral-Derived Aspergillus sp. Fungus: 13S Enantiomers as the True Natural Products. J. Nat. Prod. 2021, 84, 1353-1358. [CrossRef]

97. Pham, T.M.; Wiese, J.; Wenzel-Storjohann, A.; Imhoff, J.F. Diversity and antimicrobial potential of bacterial isolates associated with the soft coral Alcyonium digitatum from the Baltic Sea. Anton. Leeuw. 2016, 109, 105-119. [CrossRef] [PubMed]

98. Yang, S.; Sun, W.; Tang, C.; Jin, L.; Zhang, F.; Li, Z. Phylogenetic diversity of actinobacteria associated with soft coral Alcyonium gracllimum and stony coral Tubastraea coccinea in the East China Sea. Microb. Ecol. 2013, 66, 189-199. [CrossRef] [PubMed] 